Documento No. 12

\title{
OPCIONES DE POLÍTICA ECONÓMICA
}

$1979-1982$

por

Sócrates Rizzo y Leopoldo Solís

Septiembre, 1979

$\underline{\text { Las ideas contenidas en el presente ensayo son responsabilidad exclusiva del autor y no reflejan la }}$ posición del Banco de México, S.A. 
Síntesis del Documento Opciones de Política

Económica 1979-1982

Las perspectivas de crecimiento de la economía mexicana son sumamente halagadoras. Por primera vez en la historia contemporánea del país será posible fijar una tasa de crecimiento que no tenga como restricción la disponibilidad de divisas. En el pasado, las divisas y los ahorros fueron las restricciones económicas que limitaron la tasa de crecimiento del PIB real. Ambas pueden ser modificadas con las exportaciones y los impuestos al petróleo. De no ser estas variables las restricciones limitativas del desarrollo, tres obstáculos podrían constituirlo:

a) La disponibilidad de mano de obra (sobretodo la calificada).

b) La capacidad en la preparación y operación de proyectos de inversión, y

c) La restricción de una máxima monetización de los excedentes petroleros para asegurar la estabilización monetaria y financiera.

Mayores divisas y mayores ahorros domésticos permitirán cumplir los objetivos principales de la actual administración de crear suficientes empleos para absorber el crecimiento de la fuerza de trabajo y transformar la riqueza petrolera extraída en otras fuentes de ingreso permanente.

Los radicales cambios que en el futuro habrá en la estructura de los ahorros e inversiones del país, entre los financieros y no financieros y entre interno y externo, ameritan una revisión de la estrategia financiera.

Por un lado, se prevé un incremento en el financiamiento bancario a la inversión privada y por otro, el sector público se financiará menos con recursos externos y más con ahorros propios, por lo cual, requerirá de una menor transferencia de fondos del resto de la economía.

Aunque el ahorro externo que utiliza México, (que es canalizado principalmente hacia el sector público) disminuirá en 3.6 puntos porcentuales del PIB, de 1978 a 1982, el ahorro público aumentará en 4.1 puntos, de tal forma que la transferencia de ahorros del sector privado hacia el sector público descenderá de un 5.8\% del PIB en 1979 al 4.7\% en 1982. Por otro lado, la inversión Privada 
incrementará sus necesidades de crédito de un 25\% de dicha inversión en 1978 a un 29\% en 1982. Habrá, en síntesis, una mayor autodeterminación tiempo, se agudizarán las tensiones financieras y monetarias ante los importantes cambios estructurales que se avisaron. Ante estas expectativas, habrá que hacer congruente la estrategia financiera y monetaria con el logro de los grandes objetivos nacionales.

Para ordenar las opciones de política económica dentro de un escenario relevante, se ha buscado la relación causal a partir de las condiciones del mercado de trabajo, empezando por detectar la tasa de crecimiento en la producción, que permitirá encontrarle solución a su, hasta ahora, insuficiencia dinámica. Tómese en cuenta que existe un retraso de 15 a 20 años entre los cambios en la fecundidad y el aumento en la población en edad de trabajar, de tal manera que será hasta después de 1990 cuando la tasa de crecimiento de la fuerza laboral, en el mejor de los casos, empiece a descender.

Para ilustrar la congruencia entre objetivos e instrumentos de la política económica, hemos desarrollado el presente ejercicio macroeconómico. Más que indicar la trayectoria probable de la economía, presentamos un marco de referencia que nos parece útil para analizar las consecuencias y adoptar senderos alternativos en la política económica.

Para tales fines, hemos planteado, de partida, dos grandes objetivos económicos:

$1^{\circ}$.) En los próximos cuatro años, la economía debe absorber cuando menos el crecimiento de la oferta de la mano de obra y

$2^{\circ}$.) El excedente económico generado por las exportaciones petroleras debe transformarse en otras fuentes de ingreso permanente con el fin de asegurar la conservación y transferencia de la riqueza petrolera a las generaciones futuras.

Con respecto al primer objetivo, para la creación de empleos crezca al mismo ritmo que la oferta de mano de obra, sería necesario que el Producto Interno Bruto Real creciera al 7.1\% en 1979 y al $7.9 \%$ en 1980,1981 y 1982 .

Por otro lado, para garantizar la neta de conservación y transferencia de la riqueza nacional, se estimó que sería necesario agregar a la tendencia histórica que ha seguido la inversión nacional, un 
monto adicional equivalente a una cifra entre un $40 \%$ y $60 \%$ de las exportaciones petroleras, que es la proporción de "excedente económico" que hemos estimado como contenido en dichas exportaciones. De esta forma, calculamos que la economía debe invertir el $22.6 \%$ de su producto en $1979,22.8 \%$ en $1980,23.0 \%$ en 1981 y $22.9 \%$ en 1982.

Estas estimaciones incluyen los coeficientes de "inversión marginal para transformar la riqueza petrolera", que como porcentaje del producto del país, ascenderá a un $2.3 \%$ en $1979,3.6 \%$ en $1980,3.8 \%$ en $19813.7 \%$ en 1982 .

Para derivar las tasas de crecimiento del producto que se obtendría con las inversiones arriba descritas, se realizaron estimaciones del coeficiente incrementa capital-producto (CICP) que tuvo una media de 2.86 de 1950 a 1975 y de 3.98 durante 1971-1975.

En épocas de bajo crecimiento del Producto Interno Bruto Real, se observa un movimiento opuesto del coeficiente incremental capital-producto, y sucede lo contrario en épocas de recuperación. Por esa razón, para los años de proyección se ha considerado un coeficiente algo mayor al promedio en 1979, que es de 3.1 y de 2.8 para el lapso 1980-1982.

La caída en dicho coeficiente implica una mayor productividad de los acervos de capital, y está determinada por mayores usos de la capacidad instalada y del empleo de mano de obra, que a su vez, son el resultado de la recuperación del crédito real y de la estabilización de las expectativas inflacionarias.

De acuerdo con la metodología descrita, se estimó que, para cumplir con el objetivo de conservación de la riqueza, el producto real de la economía crecerá al 7.8\% para el presente año y al 8.9\% anual para el lapso 1980-1982. Asimismo, que el consumo total crecería al 6.7\% promedio anual y que éste bajaría como proporción del producto, y el ahorro externo se convertirá en inversión neta en el exterior de 1.6\% del producto en 1982.

Como puede observarse, las tasas de crecimiento del producto, para conseguir la meta de conservación de riqueza, son mayores que las necesarias para incrementar el empleo al mismo ritmo que el crecimiento de la fuerza de trabajo, por lo tanto, serán las primeras las relevantes para el desarrollo del presente ejercicio. De esta forma, sé sobrecumple el objetivo de empleo, pues con un 
crecimiento del producto del $7.8 \%$ para 1979 y $8.9 \%$ para los años restantes del sexenio, se incrementará la creación de empleos en 3.9\% en 1979 y 4\% en los siguientes períodos.

La eliminación de la restricción de divisas para los próximos años, nos permite asignarle al sector externo la función de variable de holgura para que se ajuste a las metas de Inversión y Consumo; así se estimó que el gasto nacional en inversión más consumo será mayor que el producto en 1979 y menor en 1980 y 1982. Esto significa que en el año actual, la economía necesitará de recursos externos-déficit en cuenta corriente- para cubrir el exceso de oferta que se traducirá en un superávit con el exterior.

Niveles de demanda mayores que los proyectados, incrementarían la absorción de recursos externos y se justificarían si se acepta una disminución del ahorro doméstico o una revisión de las metas de inversión. En el primer caso, se tendría que diminuir la meta de conservación de la riqueza y, en el segundo, se tendría que generar una mayor capacidad de preparación y operación de proyectos productivos, o bien, sacrificar las metas de control de la inflación. Estos ajustes, de considerarse pertinentes, podrían ser incorporados en una segunda revisión de este ejercicio.

El reciente estudio del Banco Mundial constituye una aportación útil, si bien incompleta y en partes sesgada, de la naturaleza del nuevo mundo económico en cuyo umbral se encuentra el país. Ahí se apunta que, irrestrictamente, las importaciones constituirán, la variable de ajuste o de holgura, que completamente la oferta interna y hagan más elástica a la oferta agregada. Aquí hemos adoptado un camino diferente, pensando que la apertura de la economía al exterior no es conveniente bajo cualquier circunstancia, ni parece probable que sea tan elástica mientras persistan los cuellos de botella en la producción de bienes y servicios domésticos.

Hemos estimado que los ahorros público y privado subirán en 5.3 puntos porcentuales del Producto Interno Bruto, al pasar de representar un 22.9\% del PIB en 1978 a un $26.9 \%$ del mismo agregado en 1982. Este importante incremento será explicado principalmente por el ahorro público, ya que éste aumentará en 4.1 puntos porcentuales, al pasar de un $2.5 \%$ del PIB en 1979 a $6.6 \%$ en 1982.

La eliminación de la restricción de divisas viene acompañado con un ahorro nacional creciente, pues las nuevas exportaciones están asociadas con un crecimiento en los ingresos fiscales mayores que en el gasto corriente. Esto nos indica, a primera vista, que es posible financiar mayores 
niveles de inversión pero, en el corto plazo, no sería factible hacerlo si exigimos que las nuevas inversiones se realicen con una productividad cuando menos igual al rendimiento alternativo mínimo que el país tiene al ahorrarse intereses sobre la deuda externa. Incrementar exageradamente las inversiones podría ocasionar altos costos marginales debido a los cuellos de botella que padece actualmente la economía y además, mayores presiones de demanda pondrían en peligro la estabilidad económica hasta ahora conseguida, generando así un nuevo ciclo de pare-siga.

El aumento de las importaciones no es imprescindible para lograr las metas de crecimiento, pues puede ser sustituido con incrementos de ahorro interno que liberen gasto o demanda total que no necesiten como contrapartida la oferta importada. En este aspecto destacan las políticas de subsidios de las empresas públicas y el nivel de ahorro de PEMEX, especialmente los precios internos de combustibles que son decisivos en la determinación de los niveles de ahorro público.

Nótese que lo que es válido para el ahorro interno, no lo es para el ahorro público que generan las exportaciones de petróleo, ya que de manera concomitante al aumento en las ventas al exterior de hidrocarburos se cierra el déficit de la cuenta corriente y baja el ahorro externo: con mayores exportaciones aumentaría el ahorro doméstico vía ingresos fiscales pero, simultáneamente, bajaría el ahorro externo. Se debe comentar el ahorro interno vía precios domésticos.

Los subsidios concedidos por empresas públicas y agencias gubernamentales al resto de la economía, representan casi el 6\% del Producto Interno Bruto, aproximadamente el doble del déficit de la cuenta corriente de la balanza de pagos y constituyen una amplia posibilidad de mejorar los niveles de ahorro interno. No se olvide que la participación del ahorro gubernamental y de las empresas y organismos públicos en el ahorro total es sumamente baja, consecuencia del elevado crecimiento que ha tenido el gasto corriente en esta década y de los bajos precios de los bienes y servicios vendidos por empresas públicas.

Para realizar las proyecciones, hemos supuesto que el tipo de cambio mantiene la competitividad externa de las exportaciones y de la sustitución de importaciones, o sea, un tipo de cambio real constante, que compensa los diferenciales de inflación de México con el exterior. Pero lo que nos importa destacar es que el tipo de cambio se encuentra vinculado a las condiciones del mercado de trabajo. 
Un tipo de cambio sobrevaluado haría posible en el mediano plazo una mayor absorción de recursos externos y permitiría, por lo tanto, menores requerimientos de ahorro doméstico, pero a costa de sacrificar la meta de empleo. El cumplimiento de la meta de incremento del ahorro nacional apoya no sólo el objetivo de conservación de la riqueza, sino también el de la creación de empleos.

Visto desde este ángulo, es posible concebir que no todas las divisas que se pueden conseguir a cambio de hidrocarburos pueden tener una aplicación productiva -hay una tasa óptima de extracción y - exportación que es preciso localizar, excederla será sin duda contraproducente. Tampoco es necesariamente cierto que sea preferible el extraer petróleo y convertirlo en activos financieros internacionales, a retrasar la tasa de extracción e invertir, en actividades alternativas, los recursos no usados en mayor producción petrolera. Dar elementos de juicio para encontrar la tasa adecuada de exportación es la preocupación central de este ensayo.

En la segunda parte de este trabajo se intenta examinar la correspondencia entre la exportación de petróleo, el superávit de la cuenta corriente de la balanza de pagos y el equilibrio en el mercado de dinero, es decir, la capacidad de absorción de dinero compatible con las metas de disminución gradual del aumento de precios.

Excluimos, de las opciones analizadas, la posibilidad de una estrategia de "crecimiento de inflación", pues en las condiciones actuales de la economía, una aceleración del ritmo inflacionario ocasionaría más bien una disminución del crecimiento del producto, y además, medidas correctivas tales como las de "indización”, que se podrían adoptar para evitar que se frenara el crecimiento del producto, involucrar un costo social y político mucho mayor que el costo marginal de mantener la tendencia estabilizadora hasta ahora conseguida.

Con base a todas estas consideraciones, para el análisis de las opciones de política monetaria y financiera, hemos adoptado las siguientes metas de crecimiento en los precios: 18\% para 1979, 16\% en $1980,14 \%$ en 1981 y $12 \%$ en 1982.

La tasa de inflación más el crecimiento del producto real determinan un límite máximo al crecimiento del medio circulante y, por lo tanto, a la monetización del incremento en las reservas internacionales. 
En esta área es muy importante la estimación del déficit en cuenta corriente de la balanza de pagos que, de existir, permitiría un endeudamiento externo similar, por esa cantidad más el incremento de reservas internacionales, cuyo monto completamente el ahorro interno canalizado a financiar la inversión pública.

La proyección del déficit en la cuenta corriente de la balanza de pagos estimado como la diferencia entre gasto y producto nacionales, es muy delicada, pues de ésta depende el impacto monetario del programa de exportaciones de hidrocarburos. El incremento en la demanda de dinero pone un límite a los beneficios que se podrían obtener del crecimiento, o mejor dicho de la velocidad de crecimiento del programa PEMEX.

Una vez establecido el crecimiento deseado de las reservas internacionales, y dado el déficit en cuenta corriente proyectado en la primer parte, obtenemos que, para equilibrar el mercado de divisas, será necesario un saldo de $\$ 2,066$ millones de dólares en la cuenta de capitales en 1979, \$88.5 millones en $1980,-\$ 922$ en 1981 y- \$1,879 en 1982.

La política de endeudamiento externo constituirá una variable clave en el ajuste monetario mientras permanezca sin cambio la capacidad de inversión y los cuellos de botella.

Según la alternativa 1 de PEMEX, la balanza de cuenta corriente con el exterior, del sector petrolero, es superavitaria desde 1978 con $\$ 133$ millones de dólares y alcanzará \$6,746 millones de dólares en 1982. Si a estas cifras le agregamos los programas de endeudamiento externo de PEMEX, obtenemos que la captación neta de divisas de este organismo ascenderá a \$1,628 millones en 1978, $\$ 3,693$ en 1979 , \$5,371 en 1980 , \$6,890 en 1981 y \$8,444 en 1982.

Si a esa oferta de divisas le agregamos el endeudamiento externo neto del sector no petrolero que se estima en $\$ 3,221$ millones de dólares en $1979, \$ 3,193$ en 1980, $\$ 3,793$ en 1981 y $\$ 4,252$ en 1982. Restando estos déficits a la disponibilidad de divisas calculadas más arriba, habría $\$ 1,772$ millones de dólares de exceso en 1979, \$3,478 en 1980, \$4,397 en 1981 y \$5,492 en 1982. Estas cifras nos muestran el potencial inflacionario de cumplirse las tendencias supuestas en la balanza de pagos. 
El máximo de reservas internacionales que la economía podría monetizar está determinado por las metas de abatimiento en el ritmo inflacionario y las proyecciones de crecimiento de la producción.

Será necesario esterilizar -con menos crédito al sector público o privado- para evitar presiones inflacionarias indeseables y sin mayor crecimiento real. Cuando menos, rebasar la capacidad de absorción monetaria significa una decisión de política económica enteramente distinta: ¿conviene invertir parte de los ingresos de divisas del petróleo, en el exterior? o bien ¿es preferible dejarlo en el subsuelo?

El asunto es sumamente complejo y plagado de matices, aunque en el trasfondo se puede advertir que la decisión depende de la tasa de interés que se paga por la deuda externa en comparación con el incremento esperado en el precio del petróleo.

Los intereses sobre la deuda externa, que nos ahorraríamos diminuir el endeudamiento externo, constituyen el límite inferior de la rentabilidad que se debe exigir a los proyectos de inversión nacional. Asimismo, nos marca un patrón de referencia para la periodización en la extracción del petróleo; pues si se espera que los precios mundiales del petróleo crecerán más que la citada tasa de interés, se debe conservar el hidrocarburo en el subsuelo y posponer su extracción hasta que se realice el aumento de precios.

La inferencia que se deduce del trabajo es que la monetización de los ingresos petroleros en divisas, excede los límites dictados por el crecimiento de la demanda monetaria que a su vez, están determinados por la capacidad de producción de la economía y las metas de disminución gradual de la inflación.

Además, desde el punto de vista del proyecto, mientras el precio del petróleo aumente a una tasa superior a la del rendimiento de las inversiones financieras en el exterior, como es la situación actual, la alternativa 1 de PEMEX (la más baja) presentada recientemente, resulta exagerada. Obvio es que los son aún más las otras tres.

Para evitar el impacto inflacionario y desestabilizador de la monetización del exceso de oferta de divisas discutimos enseguida varias opciones: 
En primer lugar, esterilizar los excedentes mediante el control de otras fuentes de creación de circulante, tales como disminuir crédito al gobierno, subir la tasa de encaje, o aumentar CETES, lo que implicaría una sobreinversión financiera a un caso de emergencia, constituiría un ineficiente portafolio de inversiones a largo plazo.

Decidir sobre mayores gastos de inversión y consumo (que los proyectados) para elevar el déficit en cuenta corriente, deberá hacerse en la medida en que se incremente la capacidad de inversión y se eliminen los cuellos de botella, pues de otra forma, podrían generarse otras presiones inflacionarias por el lado de los costos. Además, mayores importaciones logradas mediante una sobrevaluación cambiaria deteriorarían la meta de creación de empleos.

Nos quedan las opciones de limitar el endeudamiento externo del sector público y en particular del sector petrolero, o bien, limitar el crecimiento de las exportaciones petroleras.

Es claro que la política de endeudamiento externo debe compatibilizarse con la capacidad real que la economía tiene para absorber recursos externos, que se reflejan en el déficit en cuenta corriente más la meta de crecimiento en las reservas internacionales.

Si no se toman las medidas de política macroeconómicas adecuadas para compensar el efecto inflacionario descrito, será necesario disminuir las exportaciones petroleras que, si bien podrían justificarse desde el punto de vista de su rentabilidad, tendrían efectos globales indeseables. Una san política monetaria eliminaría así un posible "cuello de botella" a la expansión petrolera y de la economía en su conjunto. 


\section{PARTE}

\section{$\underline{\text { Inversión, Producción y Composición del Ahorro }}$}

\section{A. Creación de empleos}

A partir de la década de los 40 's, el crecimiento de la población de nuestro país empezó a acelerarse. En un principio, incidió sólo en mayores necesidades de educación y salud pero posteriormente se fue reflejando en un mayor crecimiento de la fuerza de trabajo.

Como puede observarse en el cuadro No. 1, la tasa de crecimiento medio anual de la población en la década de los 40 's fue de $2.7 \%$, incrementándose en 0.7 puntos porcentuales en la década de los 60 's y pasando por un valor intermedio de $3.1 \%$ durante la década de los 50's. Mientras tanto, el crecimiento medio anual de la oferta de trabajo en la década de los 50 's fue de $2.0 \%$ y en la de los 60 's de $2.7 \%$.

A partir de la década de los 50's, el crecimiento de la población se reflejó inicialmente en una disminución de la participación de la fuerza de trabajo en la población total y en un aumento en el coeficiente de dependencia (población menor de 14 años y mayor de 65/población comprendida entre los 15 y los 64 años de edad). Sin embargo, a partir de mediados de los 70's, el crecimiento de la fuerza de trabajo empieza a incidir en una mayor participación de la fuerza de trabajo.

Como también lo sugiere el Cuadro No. 1, el incremento de la fuerza de trabajo en los próximos quince años ya ha sido determinado por el crecimiento demográfico de las últimas décadas. Además, para absorber únicamente el crecimiento de la oferta de trabajo, se deberán crear más de 600,000 nuevos empleos anuales durante 1979 , y más de 800,000 por año, en la década de los 80 's.

Estas cifras deberán incrementarse si además se desea que el desempleo acumulado hasta 1978 empiece a descender. 
Cuadro 1

Población y Oferta de Trabajo

\begin{tabular}{|c|c|c|c|c|c|c|c|}
\hline Concepto & $\begin{array}{c}1931 \\
\mathrm{a} \\
1940 \\
\end{array}$ & $\begin{array}{c}1941 \\
\mathrm{a} \\
1950\end{array}$ & $\begin{array}{c}1951 \\
a \\
1960\end{array}$ & $\begin{array}{c}1961 \\
\mathrm{a} \\
1970 \\
\end{array}$ & $\begin{array}{c}1971 \\
\mathrm{a} \\
1980 \\
\end{array}$ & $\begin{array}{c}1981 \\
\mathrm{a} \\
1949 \\
\end{array}$ & $\begin{array}{c}1931 \\
\mathrm{a} \\
1940 \\
\end{array}$ \\
\hline 1.- Tasa de crecimiento medio anual de la población ( \% ) & 1.7 & 2.7 & 3.1 & 3.4 & 3.2 & 2.9 & 2.7 \\
\hline 2.- Tasa de crecimiento medio anual de la oferta de trabajo ( $\%$ ) & & & 2.0 & 2.7 & 3.5 & 3.7 & 3.3 \\
\hline 3.- Incremento anual promedio de la oferta de trabajo (miles de pers) & & & & & & 840 & 1,050 \\
\hline 4.- Participación de la fuerza de trabajo en el período & & & 0.31 & 0.28 & 0.26 & 0.28 & 0.30 \\
\hline 5.- Coeficiente de dependencia para el período considerado* & & 0.80 & 0.86 & 0.96 & 1.00 & & \\
\hline
\end{tabular}

Por otro lado, es necesario hacer notar que la política demográfica orientada a disminuir el crecimiento de la población, aunque tendrá un impacto en el corto plazo sobre el coeficiente de dependencia, requerirá de más de 15 años a partir del presente, para que se refleje en una reducción de la tasa de crecimiento de la oferta de trabajo. Por lo tanto, no será sino hasta la última década del presente siglo cuando la tasa de crecimiento de la oferta de trabajo, en el mejor de los casos, empiece a disminuir como resultado de una disminución de la natalidad lograda desde los 70's.

Cada vez es más difícil que la economía del país absorba productiva y permanente la creciente oferta de mano de obra debido principalmente a las crecientes distorsiones en el mercado de factores, que consisten en una creciente discrepancia entre el costo de mercado y su verdadero costo social.

El incremento esperado en la oferta de divisas, derivado de mayores exportaciones de petróleo, elimina aunque temporalmente, una de las tradicionales restricciones efectivas al ritmo de crecimiento de la economía, al hacer posible que las importaciones aumenten con gran rapidez y $\sin$ que ello provoque presiones inflacionarias o se marque un límite estrecho al volumen de endeudamiento externo.

La elevación en la tasa de crecimiento del producto que será posible lograr debido a la relajación de la restricción de divisas, no sólo provoca un aumento en el ritmo presente de generación de empleos sino que, al hacer posible que se incremente el excedente invertible, se amplían las posibilidades futuras de creación de empleos.

Considerando que en los próximos cuatro años no habrá una sustitución significativa de capital por trabajo, el crecimiento del empleo quedará determinado principalmente por el crecimiento del producto. 
Para calcular el efecto del incremento en la producción sobre el empleo, se tomaron las estimaciones de "elasticidad producto del empleo" ( $\Delta \%$ empleo/ $\Delta \%$ PIB Real) que se hicieron en una versión anterior del presente ejercicio.

$$
\begin{array}{rlrl}
1979 & =.50 & 1980 & =.45 \\
1981 & =.45 & 1982 & =.45
\end{array}
$$

Por lo tanto, para cumplir con el primer objetivo de crear empleos al mismo ritmo que la oferta de mano de obra, sería necesario que el Producto Interno Bruto Real creciera al 7.1\% en 1979 y al 7.9\% en el período 1980-1982.

Estos ritmos de crecimiento del PIB constituyen los valores mínimos aceptables para cumplir con una meta razonable de creación de empleos: absorber, cuando menos, el incremento en la fuerza de trabajo.

\section{B. Inversión total}

La conservación de la riqueza nacional y en particular de las nuevas riquezas petroleras, constituyen el segundo objetivo de política económica. Para tal efecto, deben plantearse las metas de inversión que cumplan adecuadamente con tal objetivo.

Se proyectó exógenamente un coeficiente de inversión total respecto al producto, formado de dos componentes:

a) Un coeficiente "inversión histórica" que refleja la tendencia de la economía hasta antes de los descubrimientos petroleros para, con esta perspectiva, separar las nuevas condiciones creadas por el incremento de la riqueza petrolera. ${ }^{*}$

\footnotetext{
NAFINSA y Banco de México, "Evolución del Economía en el Período 1978 - 1982 (una primera exploración)". Mimeografiado, abril de 1978. Véase también el apéndice No. 2 del presente documento.

* Dentro de la "tendencia histórica" está ya incorporada la inversión norma para cubrir las necesidades nacionales de energéticos.
} 
b) Un segundo componente consiste en los montos de inversión adicional necesarios para compensar el agotamiento de las reservas petroleras extraídas y exportadas, con el fin de transformar dichos recursos no renovables en otras fuentes permanentes de ingreso y de empleo.

El "coeficiente histórico" de inversión para condiciones normales de crecimiento se encuentra en alrededor de 20.9\% del PIB, ${ }^{* *}$ pero como 1978 y 1979 son años de recuperación de la inversión privada y de una alta inversión pública, sus coeficientes serán mayores al promedio. Para 1978 se estimó un coeficiente de $23.0 \%$ y uno ligeramente menor para 1979, de $21.9 \%$.

La inversión marginal para reponer o sustituir el agotamiento de los recursos petroleros exportados es igual al monto de las "cuasi rentas" incorporadas en el valor de las exportaciones petroleras, que son una expresión de la "riqueza exportada". Para su estimación, al valor de las exportaciones se le dedujeron los costos de los insumos intermedios, el valor de las erogaciones por mano de obra y el costo de oportunidad del capital."

Para la cuantificación, se tomó la proyección de la “Alternativa I" prestada por PEMEX el día 9 de febrero de 1979. Este supuesto se hace para usarlo como un punto de referencia básico y no involucra la aceptación de dicha alternativa como la óptima.

Como se puede observar en el Cuadro Básico "B" del apéndice 5, se estimó que la renta petrolera constituye entre un 40 y $60 \%$ de los ingresos corrientes. ${ }^{*}$ Suponemos, además, que dicho coeficiente es creciente con el aumento de producción, debido a economías a escala. Los resultados se presentan a continuación:

** Se calculó el coeficiente de inversión histórica como la media del período 1960-1977.

$$
\sum_{1960}^{1977} \frac{\mathrm{IFBt}}{\mathrm{PIBt}-1} / \mathrm{n}=20.9
$$

** Al capital invertido hasta 1978 se le adjudicó un costo de oportunidad menor que a las futuras inversiones.

* Si evaluamos a precios internacionales las reservas probadas de 40,000 millones de barriles de gas y petróleo y suponemos que el $50 \%$ de dicho valor constituye riqueza neta, la riqueza petrolera probada, equivale al capital total (no petrolero) de la economía en 1978 (suponiendo una relación capital - producto de 3.0). 


\section{Cuadro 2}

\section{Renta Petrolera Exportada}

(Miles de millones de pesos a precios de 1972 y \%)

\begin{tabular}{lrrrrr}
\hline \multicolumn{1}{c}{ C o n c e p t o } & 1978 & 1979 & 1980 & 1981 & \multicolumn{1}{c}{1982} \\
\hline Exportaciones & 15.5 & 33.4 & 47.6 & 54.7 & 58.0 \\
Costo de Ventas (\%) Ventas & 60 & 50 & 40 & 40 & 40 \\
Renta petrolera exportada & 6.2 & 16.7 & 28.5 & 32.8 & 34.8 \\
\hline
\end{tabular}

La inversión, adicional a la "tendencia histórica, puede darse sin mayor dificultad, debido al incremento de la capacidad de inversión que resulta de la eliminación de la tradicional restricción en la disponibilidad de divisas, aunque como ya se ha mencionado, esta capacidad, si bien aumenta de manera importante, no es ilimitada.

Con base en la información del Banco de México para el período 1960-1977, se estimó que la inversión para reponer el consumo de capital fijo es igual al 7.5\% del PIB, dado que la depreciación representa entre el 2\% y el 3\% del acervo de capital, y se considera, además una relación media capitalproducto de 3.

La variación de inventarios se estimó en $2.5 \%$ del PIB, de acuerdo con los valores que tuvo dicha variable durante el período 1960-1976. Sin embargo, en 1978 se supone que es mayor que la histórica (4.0\%), pero menor que en 1977 (4.77\% del PIB).

En el cuadro No. 3 se presenta el resumen de las estimaciones de los diferentes rubros de inversiones antes explicados.

\section{Cuadro 3}

Proyecciones de Inversiones

(Miles de millones de pesos de 1972)

\begin{tabular}{|c|c|c|c|c|c|c|c|c|}
\hline \multirow{2}{*}{ Concepto } & \multicolumn{2}{|c|}{1979} & \multicolumn{2}{|c|}{1980} & \multicolumn{2}{|c|}{1981} & \multicolumn{2}{|c|}{1982} \\
\hline & Absoluto & $\% \mathrm{PIB}$ & Absoluto & $\% \mathrm{PIB}$ & Absoluto & $\% \mathrm{PIB}$ & Absoluto & $\% \mathrm{PIB}$ \\
\hline 1.- Inversión Fija Bruta Histórica & 148.3 & 20.3 & 152.6 & 19.2 & 166.2 & 19.2 & 181.0 & 19.2 \\
\hline 2.- Consumo del Capital & 54.8 & 7.5 & 59.6 & 7.5 & 64.9 & 7.5 & 70.7 & 7.5 \\
\hline $\begin{array}{l}\text { 3.- Inversión marginal para } \\
\text { transformar la riqueza petrolera }\end{array}$ & 16.7 & 2.3 & 28.5 & 3.6 & 32.8 & 3.8 & 34.8 & 3.7 \\
\hline 4.- Inversión Fija Bruta Total & 165.0 & 22.6 & 181.1 & 22.8 & 199.0 & 23.0 & 215.8 & 22.9 \\
\hline
\end{tabular}




\section{El coeficiente incremental capital-producto (CICP)}

Con objeto de derivar las tasas de crecimiento en el producto que se obtendrían con las inversiones propuestas en la sección anterior, se estimó un coeficiente incremental capital-producto de 3.9 en 1978, 3.1 en 1979 y uno ligeramente menor para el período 1980-1982 de 2.8.

El coeficiente medio capital-producto registró un promedio de 2.83 de 1950 a 1975 mostrando una ligera tendencia decreciente de 1950 a 1970 y creciente de 1970 a 1975 . El coeficiente incremental no muestra ninguna tendencia clara pero desde luego, registra mayores variaciones que el coeficiente medio. El CICP tuvo una media de 2.86 en el período 1950 a 1975 y de 3.98 durante 1971-1975. Los valores de estos coeficientes se muestran en el siguiente cuadro.

Cuadro 4

Coeficiente Medio e Incremental Capital - Producto ${ }^{1 /}$

\begin{tabular}{lrrrrrrrrr}
\hline \multicolumn{1}{c}{ C o n c e p t o } & $51-55$ & $56-60$ & $61-65$ & $66-70$ & $71-75$ & 1976 & 1977 & $51-70$ & $51-75$ \\
\hline$(K / Q)$ Coeficiente Medio & 2.96 & 2.88 & 2.96 & 2.64 & 2.75 & 3.03 & 3.15 & 2.80 & 2.81 \\
& & & & & & & & & \\
$(\Delta K / \Delta Q)$ Coeficiente Incremental & 2.63 & 2.76 & 2.38 & 2.54 & 3.98 & 10.0 & 7.0 & 2.60 & 2.86 \\
Crecimiento medio anual del PIB & 5.58 & 5.71 & 7.10 & 6.90 & 5.70 & 2.1 & 2.8 & 6.32 & 6.19 \\
Inversión/PIB & 14.62 & 15.76 & 16.90 & 17.53 & 22.69 & 21.0 & 19.6 & 16.43 & 17.73 \\
\hline
\end{tabular}

Durante los períodos de disminución en el crecimiento del PIB se observa un drástico incremento en el CICP, y en forma simétrica durante los períodos de recuperación se observa una disminución en dicho coeficiente. Esto está íntimamente correlacionado con las variaciones en el crédito real, medio circulante y precios, pues los cambios en el CICP están asociados a variaciones en el uso de la capacidad instalada.

Para 1978 se supone un CICP mayor que el promedio porque en ese año se presentó la recuperación de las inversiones que aún no se traducen plenamente en la producción y, además aunque prevalece todavía la capacidad ociosa, están presentes algunos cuellos de botella. En 1979 se estima un 
CICP algo menor pero todavía superior al promedio pues aún persisten los estrangulamientos y continúa un alto ritmo de inversiones.

La estimación de un CICP de 2.8 para los tres últimos años, incorpora dos tendencias opuestas y compensatorias:

a) Por un lado se expresa un movimiento a la alza derivado de una mayor intensidad en capital, derivado de una mayor participación pública en la última década.

b) Por otra parte, debido al aumento en la rentabilidad del capital en el sector petrolero, se prevé un abatimiento del $\mathrm{CICP}^{* *}$. Este efecto se refleja en las cuasi-rentas generadas por ese sector al producir un valor mayor que el costo de oportunidad de los mismos utilizados en la producción.

\section{Crecimiento del Pib real}

La tasa anual de crecimiento del PIB real de la economía en su conjunto se estimó de la siguiente manera:

$$
G_{t}=\frac{\mathrm{b}_{\mathrm{tp}}}{w t}+\frac{\mathrm{b}_{\mathrm{th}}}{\mathrm{wt}}
$$

donde:

$G_{t}=$ tasa de crecimiento del PIB real en el período " $t "$

$b_{t h}=$ coeficiente de inversión histórica en el año " $t$ " como proporción del PIB del período " $t-1 "$

\footnotetext{
* Para una discusión más amplia, véase el Apéndice No. 7.

** El incremento en la producción de barriles diarios entre 1976 y 1982 es de 2.9 veces (2284/2800.9) y, por otro lado, el incremento en el acervo de capital de 1977 a 1982 (a precios de 1976) con respecto al acervo de capital en 1976 es de 2.1 veces (263.9/128.3), por lo que es de suponer que el CICP petrolero disminuiría. Además una proporción creciente del producto físico se exporta, lo que se realiza a un precio significativamente mayor al interno, por lo cual el CICP petrolero disminuye aún más.
} 
$b_{t \mathrm{p}}=$ coeficiente marginal de inversiones para transformar los recursos no renovables exportados en otras fuentes permanentes de ingreso.

$w_{t}=$ CICP en el año "t"

Con base en estos elementos se obtuvieron las siguientes proyecciones:

Cuadro 5

Coeficiente Medio e Incremental Capital - Producto

\begin{tabular}{lrrrrr}
\hline C o n c e p t o & 1978 & 1979 & 1980 & 1981 & 1982 \\
\hline $\begin{array}{l}\text { 1. Inversión para compensar el agotamiento del recurso } \\
\text { petrolero exportado *. (miles de millones de pesos 1972) }\end{array}$ & 6.2 & 16.7 & 28.5 & 32.8 & 34.8 \\
2. PIB del año t-1 (miles de millones de pesos de 1972) & 637.7 & 677.2 & 730.0 & 795.0 & 865.8 \\
3. Coeficiente petrolero $(1) /(2)\left(\mathrm{b}_{\mathrm{tp}}\right)(\%)$ & 0.0098 & 0.0247 & 0.0390 & 0.0412 & 0.0402 \\
& & & & & \\
4. Coeficiente de inversión histórico $\left(b_{t \mathrm{~h}}\right)(\%)$ & 3.230 & 0.219 & 0.209 & 0.209 & 0.209 \\
5. CICP & 6.2 & 7.8 & 8.9 & 8.9 & 8.9 \\
6. Crecimiento del PIB real $\left(G_{t}\right)(\%)$ & & & &
\end{tabular}

El PIB Real crecerá al 8.1\% en promedio de 1978 a 1982, y si substraemos del PIB total el incremento de la riqueza petrolera exportada (cuasi-rentas) obtenemos un "PIB revisado" que crece al $7.8 \%$.

En 1980 el "PIB revisado" representa el 96.4\% del PIB es decir, el 3.6\% del PIB total representada las cuasi-rentas exportadas.

Este 3.6\% refleja una parte del PIB que representa, más que un ingreso corriente, un ingreso derivado de la venta de un activo. Por eso, dedicar dicha proporción del PIB a la inversión, no significa un esfuerzo de ahorro adicional, sino solo su transformación dentro de la composición de los activos.

\footnotetext{
Tomado del cuadro No. 2.
} 
Partiendo de las proyecciones realizadas por PEMEX, se obtuvo la aportación del sector petrolero al PIB y, de esa forma se separó a la economía en dos sectores, como puede observarse a continuación y en el cuadro básico que constituye el apéndice No. 1 de este documento.

\section{Cuadro 6}

PIB de los Sectores Petroleros y No Petroleros

\begin{tabular}{|c|c|c|c|c|c|c|c|c|c|}
\hline \multirow{3}{*}{ Concepto } & \multicolumn{3}{|c|}{1978} & \multicolumn{3}{|c|}{1979} & \multicolumn{3}{|c|}{1980} \\
\hline & Absoluto & $\%$ & Crec. & Absoluto & $\%$ & Crec. & Absoluto & $\%$ & Crec. \\
\hline & & PIB & & & PIB & & & PIB & \\
\hline PIB Real de la Economía & 677.2 & 100 & 6.2 & 730.0 & 100 & 7.8 & 795.0 & 100 & 8.9 \\
\hline PIB del Sector Petrolero & 26.0 & 3.8 & 27.5 & 38.1 & 5.2 & 46.5 & 50.6 & 6.4 & 32.8 \\
\hline PIB del Resto de la Economía & 651.2 & 96.2 & 5.5 & 691.9 & 94.8 & 6.3 & 744.4 & 93.6 & 7.6 \\
\hline
\end{tabular}

\begin{tabular}{lrrrrrrrr}
\hline \multirow{2}{*}{\multicolumn{1}{c}{ C o n c e p to }} & \multicolumn{3}{c}{1981} & \multicolumn{3}{c}{1982} & & \\
\cline { 2 - 9 } & Absoluto & \multicolumn{1}{c}{$\%$} & Crec. & Absoluto & \multicolumn{1}{c}{ Crec. } & \multicolumn{1}{c}{ \% } & Cre \\
& & PIB & & & PIB & & PIB & \multicolumn{1}{c}{ c. } \\
\hline PIB Real de la Economía & 865.8 & 100 & 8.9 & 942.9 & 100 & 8.9 & 100 & 8.1 \\
PIB del Sector Petrolero & 55.7 & 6.4 & 10.1 & 59.8 & 6.3 & 7.4 & 5.6 & 24.9 \\
PIB del Resto de la Economía & 810.1 & 93.6 & 8.8 & 880.1 & 93.7 & 9.0 & 94.4 & 7.4 \\
\hline
\end{tabular}

Según estas estimaciones, el PIB del sector petrolero pasará de significar el 3.2\% del PIB total en 1977 al $6.3 \%$ en 1982, y registrará un crecimiento medio anual de $24.9 \%$ durante el período 1978 1982. El crecimiento del mismo, es porcentualmente elevado en 1978, 1979 y 1980, período durante el cual crece a una tasa anual promedio del $25.6 \%$ en términos reales.

El PIB del resto de la economía crecerá a una tasa anual promedio del $7.4 \%$ siendo menor durante los primeros años en los que el crecimiento del PIB petrolero es mayor.

El cálculo de la aportación del sector petrolero al valor agregado de la economía se podría incrementar sustancialmente si se valoran las ventas internas de PEMEX a precios internacionales que representen su costo de oportunidad social. Esta cuantificación es útil para estimar el monto de los subsidios a la inversión y el consumo, implícitos en los precios de PEMEX. ${ }^{*}$ El subsidio al consumo, doméstico es tan grande como el valor de las rentas internas y representa un $30 \%$ de las ventas totales (incluyendo exportaciones) ajustadas por los costos de oportunidad.

\footnotetext{
PEMEX ha definido, correctamente, la diferencia en precios internos y externos de la gasolina y los derivados como parte del excedente petrolero canalizado al resto de la economía, pero en la medida en que se subsidia al consumo, viola la condición de transformación de capital petrolero a no petrolero. Ver apéndices 5 y 6 de este documento.
} 
Las tasas de crecimiento del PIB Real, obtenidas anteriormente cumplen con el objetivo de conservación de la riqueza y son mayores que las necesarias para incrementar el empleo al mismo ritmo que el crecimiento de la fuerza de trabajo, que es el primer objetivo económico planteado en el presente ejercicio. A continuación se presentan dichas estimaciones.

\section{Cuadro 7}

Mercado de Trabajo

(Millones de personas y \%)

\begin{tabular}{llrrrr}
\hline \multicolumn{1}{c}{ C o n c e p t o } & \multicolumn{1}{c}{1978} & \multicolumn{1}{c}{1979} & 1980 & 1981 & 1982 \\
\hline 1. Población económicamente activa & 17.8 & 18.4 & 19.1 & 19.8 & 20.5 \\
2. Población ocupada & 16.4 & 17.0 & 17.7 & 18.4 & 19.1 \\
3. Tasa de crecimiento de la ocupación (\%) & 3.6 & 3.9 & 4.0 & 4.0 & 4.0 \\
4. Coeficiente de desocupación (\%) & 7.8 & 7.6 & 7.3 & 7.1 & 6.8 \\
5. Crecimiento de la oferta de trabajo & 3.55 & 3.55 & 3.55 & 3.55 & 3.6 \\
6. Tasa de crecimiento del PIB & 6.2 & 7.8 & 8.9 & 8.9 & 8.9 \\
\hline
\end{tabular}

De esta forma se sobrecumple el objetivo de absorber cuando menos el crecimiento de la oferta de mano de obra, pues con un crecimiento del producto del $7.8 \%$ para 1979 y de $8.9 \%$ en el período 1980-1982 se incrementará la creación de empleos en 3.9\% durante 1979 y en un 4.0\% en los años restantes. Entonces, las tasas de crecimiento del PIB, derivadas del $2^{\circ}$. Objetivo se convierte en las relevantes para el resto del presente documento.

\section{E. Consumo total y absorción}

El consumo total (público más privado), se proyecta como función del ingreso permanente. No se incorporó la disponibilidad de crédito por ser un factor no significativo en el comportamiento del consumo total, aunque posiblemente si lo sea para ciertos componentes del consumo privado.

Tomando datos anuales de 1961 a 1976 del Producto Interno Neto y del Consumo total, ambos deflacionados con los precios de 1960 , se obtuvo el siguiente ajuste. ${ }^{* *}$

$$
C_{t}=4.078+0.5674 \mathrm{Y}_{\mathrm{t}}+0.3987 \mathrm{C}_{\mathrm{t}-1}
$$

\footnotetext{
* Que se calcula con el método de expectativas adaptables de ingresos corrientes pasados y ponderados de manera decreciente.

** Véase el apéndice 4 en el que se explica la derivación y estimación de la función consumo.
} 
$R^{2}=.9981$

donde

$C_{\mathrm{t}}=$ consumo total del año " $\mathrm{t} "$

$Y_{t}=$ producto interno neto del año " $\mathrm{t} "$

Suponer que las cuasi-rentas petroleras se reinvierten, implica que el consumo queda en función del producto excluyendo dichas rentas a lo que hemos llamado "Producto Interno Neto".

Como se muestra en el cuadro No. 8, las proyecciones de consumo total obtenidas, manifiestan una elasticidad-producto creciente y resultan en un consumo per cápita también creciente.

Cuadro 8

Elasticidad $=$ Producto del Consumo

\begin{tabular}{lrrrrr}
\hline \multicolumn{1}{c}{ C o n c e p to } & \multicolumn{1}{c}{1978} & 1979 & 1980 & 1981 & 1982 \\
\hline Consumo/PIN & 80.8 & 80.5 & 80.5 & 79.6 & 79.4 \\
Crecimiento del Consumo per cápita $1 /$ & 1.4 & 2.9 & 4.1 & 5.5 & 6.2 \\
Tasa de crecimiento del Consumo total (\%) & 4.3 & 5.7 & 6.8 & 8.1 & 8.7 \\
Elasticidad producto del Consumo Total & 0.84 & 0.92 & 0.92 & 0.93 & 0.97 \\
\hline 1/ Se calculó en base a un crecimiento de la población de 3.2 en 1977, 2.9 en 1978 2.8 en 1979, \\
2.7 en 1980, 2.6 en 1981 y 2.5 en 1982.
\end{tabular}

La proyección del consumo total tiene un comportamiento más estable que las proyecciones desagregadas de diferentes componentes del mismo.

La "Absorción Real Total” se define como la suma del consumo y la inversión totales del sector público y privado y se estima como enseguida se describe:

\footnotetext{
* La función consumo ya incorpora el efecto de mayor riqueza en la medida en que dicha riqueza se concreta en incrementos del PIN mayores a la tasa histórica. Además, el consumo per cápita tiene una aceleración a lo largo del período.
} 
Absorción Real

(Cifras en miles de millones de pesos de 1972)

$\begin{array}{lll}1978=674.0 & 1981=832.2 \\ 1979=713.1 & 1982=904.5 \\ 1980=766.8 & \end{array}$

y las tasas de crecimiento anual:

$\begin{array}{rlr}1979=5.8 \% & 1980=7.5 \% \\ 1978=8.5 \% & 1982=8.7 \%\end{array}$

F. Balanza de mercancías y servicios y ahorro externo

La balanza de mercancías y servicios actúa como la variable de ajuste para los desequilibrios del mercado de bienes y servicios. De esta manera, un exceso de absorción con respecto a la producción corriente de la economía se resuelve mediante un exceso de importaciones sobre exportaciones y, por lo tanto, a través de la cuenta corriente. El saldo de la balanza de mercancías y servicios no factoriales se obtiene como la diferencia entre la absorción y el PIB que hemos proyectado anteriormente.

La absorción es mayor que el producto cuando la inversión supera al ahorro nacional. La diferencia se cubre a través del déficit en cuenta corriente, es decir, que el exceso de demanda por bienes se financia o compensa con ahorro externo.

Como se observa en el cuadro No. 9, es de preverse un ahorro externo negativo en 1980, 1981 y 1982, (la absorción es menor que el PIB) lo que constituye un superávit en la cuenta corriente de la balanza de pagos del país. 
Cuadro 9

Balanza de Pagos

( $\%$ del PIB )

\begin{tabular}{llrrrrr}
\hline \multicolumn{1}{c}{ C o n c e p t o } & 1978 & 1979 & 1980 & 1981 & 1982 \\
\hline 1. Déficit en cuenta corriente total =2+3 & -2.6 & -1.1 & 0.4 & 1.1 & 1.5 \\
2. Sector petrolero & 0.1 & 2.0 & 3.1 & 3.8 & 4.1 \\
3. Resto de la economía & -2.7 & -3.1 & -2.7 & -2.7 & -2.6 \\
$\begin{array}{l}\text { 4. Superávit en mercancías y servicios no } \\
\text { factoriales }\end{array}$ & 0.5 & 2.3 & 3.5 & 3.9 & 4.1 \\
\hline
\end{tabular}

Si bien la economía en su conjunto no usa ahorro externo, el sector no petrolero sí registra un déficit en su cuenta corriente con el exterior.

El saldo en la balanza de mercancías y servicios no factoriales es aún mayor que el de la cuenta corriente, lo cual es indicio de que la absorción de recursos corrientes será menor que el PIB, ya que una gran parte de la misma se dedica a los servicios factoriales que constituyen un pago por capital importado en el pasado.

El uso que se haga del ahorro externo queda limitado por la capacidad de la economía para incrementar inversiones rentables.

Esta capacidad se ve aún más restringida si exigimos estándares mínimos de productividad social.

Sería posible también, mediante mayores niveles de consumo, incrementar el déficit de la cuenta corriente pero, si ese fuera el caso, implicaría una disminución del ahorro interno que sería sustituido por más ahorro externo conservando sin cambio la inversión total. Esto sería equivalente a usar exportaciones adicionales de petróleo para financiar el consumo, o también si se financia con más deuda externa, esta última tendría que pagarse en el futuro con exportaciones petroleras y, en tal forma, se viola el principio anotado inicialmente de transformar la riqueza petrolera en otras fuentes permanentes de ingreso para conservar, cuando menos, inalterada la riqueza del país. 
G. Estructura del ahorro

El ahorro nacional bruto se obtiene como la diferencia entre el Producto Nacional Bruto y el Consumo Total, o bien, como Inversión Total menos Ahorro Externo.

Como puede observarse en el cuadro No. 10, el coeficiente de ahorro nacional aumenta un 4.0 puntos porcentuales pues pasa de un $22.9 \%$ en 1978 a un $26.9 \%$ en 1982 . Dicho aumento compensa la disminución en el uso del ahorro externo.

Cuadro 10

Composición del Ahorro

( \% del PIB )

\begin{tabular}{llrrrr}
\hline \multicolumn{1}{c}{ C o n c e p t o } & \multicolumn{1}{c}{1978} & \multicolumn{1}{c}{1979} & \multicolumn{1}{c}{1980} & \multicolumn{1}{c}{1981} & \multicolumn{1}{c}{1982} \\
\hline 1. Inversión Fija Bruta & 22.5 & 22.6 & 22.8 & 230 & 22.9 \\
2. Variación de Inventarios & 3.0 & 2.5 & 2.5 & 2.5 & 2.5 \\
3. Ahorro Externo & 2.6 & 1.1 & -0.4 & -1.1 & -1.5 \\
4. Ahorro Nacional & 22.9 & 24.0 & 25.7 & 26.5 & 26.9 \\
5. Ahorro Público & 2.5 & 4.2 & 5.8 & 6.2 & 6.6 \\
6. Ahorro Privado & 20.4 & 19.8 & 19.9 & 20.3 & 20.3 \\
\hline
\end{tabular}

Se estima que el incremento del ahorro del sector público será mayor que la suma del incremento en su inversión y de la disminución del ahorro externo usado por el gobierno, por lo tanto, no se requiere de un gran esfuerzo en la generación de ahorros privados. Los cálculos del ahorro corriente bruto del sector público se presentan en el apéndice No. 3.

El ahorro privado se obtiene como residuo y es igual al ahorro nacional menos el ahorro público. El ahorro nacional es igual al PNB menos el Consumo Total proyectado.

Las proyecciones de ahorro podrían disminuir si las estimaciones de consumo total se incrementan al introducir el efecto que un aumento inusitado en la riqueza nacional podría tener sobre dicha variable.

\footnotetext{
Esto supone que el sector privado internaliza el incremento de la riqueza que está en poder del estado, lo cual podría explicarse con la expectativa de una reducción del incremento de carga fiscal, mayores niveles de consumo público o de infraestructura subsidiada.
} 
Con un incremento en la estimación de consumo se aumentaría el uso del ahorro externo y disminuiría el ahorro interno $\mathrm{y}$, en particular, el ahorro público. Permitir este comportamiento implicaría disminuir la meta de conservación de la riqueza nacional, como ya lo hemos analizado con autoridad. Por ejemplo, si se supone que la propensión media a ahorrar (pública más privada) no aumenta, esto es, que el coeficiente consumo total/PIB se mantiene constante, el uso de ahorro externo aumenta en relación a las proyecciones anteriores según se describe en el siguiente cuadro:

\author{
Cuadro 11 \\ Relación del Ahorro Externo con el Producto*
}

(\%)

\begin{tabular}{rccccc}
\hline C o n c e p t o & 1978 & 1979 & 1980 & 1981 & 1982 \\
\hline Consumo Total/PIB & 74.0 & 74.0 & 74.0 & 74.0 & 74.0 \\
Ahorro Externo/PIB & 2.8 & 4.2 & 2.5 & 2.3 & 1.9 \\
\hline
\end{tabular}




\section{PARTE}

\section{Comportamiento Monetario y Financiero}

\section{A. Equilibrio en el mercado de dinero}

Un requisito esencial para la recuperación económica en 1979 y 1980 consiste en el abatimiento de las expectativas inflacionarias y una mayor participación del sector financiero en la canalización de los ahorros. En particular, es necesario que en 1979, la tasa de inflación no sea mayor a la registrada durante 1978. En el presente ejercicio se estableció una restricción monetaria que consiste en mantener el crecimiento del medio circulante acorde con las metas de disminución gradual del aumento de precios. Este objetivo elimina la posibilidad de un crecimiento en el PIB a través de una expansión exagerada de la liquidez y aconseja vigilar estrechamente la monetización de los excedentes de divisas. El proceso de estabilización garantiza, por su parte, la permanencia de un crecimiento real sostenido, evitando los efectos de pare-siga que resultan de una erupción inflacionaria intempestiva.

El descenso gradual de la inflación se justifica con base en las siguientes consideraciones:

a) Se desean evitar los costos del desempleo transitorio, asociados a un brusco descenso en la inflación.

b) En el corto plazo, no parece factible lograr una intensa y rápida apertura al exterior para amortiguar las presiones inflacionarias con mayores importaciones y, aún si esto fuera factible, resultaría en una reducción del ahorro interno y por ende en el incumplimiento de la meta de conservación de la riqueza total petrolera y no petrolera. El principal problema está en las dificultades para incrementar, en el corto plazo, la inversión socialmente productiva.

Para 1979 se propone una meta de inflación similar a la de 1978, y de 1980 en adelante es decreciente hasta llegar a un 12\% en 1982. 
Una tasa de inflación en el año corriente superior a la del año pasado, pondría en peligro el proceso de estabilización que hasta ahora se ha seguido y, si además mantenemos fija la tasa de cambio, cambiaría la perspectiva general de la balanza de pagos. Esta última posibilidad no está contemplada en el presente ejercicio.

A continuación se presentan las metas de crecimiento del PIB nominal.

Cuadro 12

Metas de Crecimiento del PIB Nominal

\begin{tabular}{lrrrr}
\multicolumn{1}{c}{$(\%)$} & & & \\
\multicolumn{1}{c}{ C o n c e p t o } & 1979 & 1980 & 1981 & 1982 \\
\hline Tasa de crecimiento del PIB nominal & 27.2 & 26.3 & 24.1 & 22.0 \\
Tasa de inflación & 18.0 & 16.0 & 14.0 & 12.0 \\
Tasa de crecimiento del PIB real $^{*}$ & 7.8 & 8.9 & 8.9 & 8.9 \\
\hline
\end{tabular}

El crecimiento de la demanda de dinero que se proyecta a continuación, se obtiene a través de una elasticidad ingreso igual a la unidad y suponiendo que, a fines de 1978 , el mercado monetario se encuentra en equilibrio. Los resultados obtenidos se presentan en el siguiente cuadro.

Cuadro 13

Crecimiento de la Demanda de Dinero y de la Base Monetaria (Millones de pesos a precios corrientes y \%)

\begin{tabular}{lrrrr}
\hline \multicolumn{1}{c}{ C o n c e p t o } & \multicolumn{1}{c}{1979} & \multicolumn{1}{c}{1980} & \multicolumn{1}{c}{1981} & \multicolumn{1}{c}{1982} \\
\hline Tasa de crecimiento del PIB nominal & 27.2 & 26.3 & 24.1 & 22.0 \\
Demanda de dinero & 328,303 & 414,647 & 514,577 & 627,784 \\
Incremento deseado en $M_{1}$ & 70,203 & 86,344 & 99,930 & 113,207 \\
Incremento deseado en la Base Monetaria & 97,504 & 119,922 & 138,792 & 157,232 \\
\hline
\end{tabular}

Los incrementos deseados tanto en la oferta monetaria $-\left(M_{1}\right)$ como de la base monetaria son los adecuados para mantener el mercado monetario en equilibrio, dadas las metas de crecimiento del PIB nominal.

\footnotetext{
* Tomando del cuadro No. 6 de la primera parte de este documento.
} 
El valor asignado a la elasticidad ingreso de la demanda por dinero parece razonable en vista del proceso de abatimiento de las expectativas inflacionarias durante el período 1978-1982.

Para derivar el incremento necesario en la base monetaria se utilizó un multiplicador de .72, valor que parece congruente con las otras variables financieras, tomando en cuenta que el coeficiente de billetes y monedas a depósitos a la vista regresará a su nivel de equilibrio después del brusco incremento que registró durante 1976 y 1977.

\section{B. Fuentes de monetización}

Las principales fuentes de crecimiento de la base monetaria son el incremento en las reservas internacionales y el crédito otorgado por el Banco de México al Gobierno Federal y a los bancos.

Hemos supuesto que el tipo de cambio mantiene la competitividad externa de las exportaciones y de la sustitución de importaciones, o sea, un tipo de cambio real constante, que compensa los diferenciales de inflación de México con el exterior, y además, que el tipo de \$22.7 pesos por dólar es una tasa de equilibrio a principios de 1979.

La política de una tasa de cambio constante en "términos reales" permite manejar autónomamente la política monetaria y en particular a la oferta monetaria.

En contraste, un régimen de paridades fijas en "términos nominales" y excluyendo adiciones a los controles comerciales y cambiarios dificulta la posibilidad de controlar el circulante. En este caso, el aislamiento de la influencia externa sólo se logra en la medida en que se sobrevalúe la paridad mediante mayores controles comerciales.

Una política cambiaria de tasa real constante requiere de una práctica congruente de flexibilización de tasas internas de interés que hagan posible un equilibrio adecuado entre los rendimientos (ajustados por cobertura cambiaria) de los activos en dólares y pesos. 
Si suponemos inicialmente que la única fuente de crecimiento de la base monetaria está constituida por el incremento en las reservas internacionales, obtenemos los resultados que se presentan en el cuadro No. 14.

El supuesto de que la única fuente de crecimiento de la base monetaria es el incremento en reservas internacionales sería equivalente a adoptar un sistema similar al "patrón oro" y sólo sirve como una hipótesis inicial para presentar el caso extremo de máxima monetización de los excedentes de divisas.

\section{Cuadro 14}

Hipótesis de Máxima Monetización de Reservas Internacionales

(En millones)

\begin{tabular}{lrrrr}
\hline \multicolumn{1}{c}{ C o n c e p t o } & 1979 & 1980 & 1981 & \multicolumn{1}{c}{1982} \\
\hline Incremento en la base monetaria (pesos) & 97,504 & 119,922 & 138,792 & 157,232 \\
Tasa de cambio pesos/dólares & 25.3 & 27.9 & 29.5 & 30.5 \\
Incremento en las reservas internacionales (pesos) & 97,504 & 119,922 & 138,792 & 157,232 \\
Incremento en las reservas internacionales (dólares) & 3,854 & 4,292 & 4,721 & 5,155 \\
\hline
\end{tabular}

Si éste fuera el caso, la entrada neta de capitales necesaria para el equilibrio de la balanza de pagos sería la que se asienta en los renglones 3 y 4 del siguiente cuadro.

\section{Cuadro 15}

Entrada Neta de Capitales con Monetización Máxima de Divisas

(En miles de millones de pesos o millones de dólares a precios corrientes)

\begin{tabular}{lrrrr}
\hline \multicolumn{1}{c}{ C o n c e p t o } & \multicolumn{1}{c}{1979} & \multicolumn{1}{c}{1980} & \multicolumn{1}{c}{1981} & \multicolumn{1}{c}{1982} \\
\hline Variación en las reservas internacionales (pesos) & 97.5 & 119.9 & 138.8 & 157.2 \\
Saldo en cuenta corriente (pesos) & -27.9 & 13.8 & 44.1 & 76.0 \\
Entrada neta de capitales (pesos) & 125.4 & 106.1 & 94.7 & 81.2 \\
Entrada neta de capitales (dólares) & 4.957 & 3.803 & 3.210 & 2.662 \\
\hline
\end{tabular}

La entrada de capitales proyectada no parece exagerada a la luz de la experiencia reciente, pero sí excesivo e innecesario un incremento en las reservas internacionales superior a los $\$ 3,800$ 
millones de dólares anuales. ${ }^{*}$ Este es el caso en el que el ahorro monetario se destina principalmente a inversión financiera, es decir, que se coloca en activos sobre el exterior.

Es conveniente el aumento en las reservas internacionales si cumplen la función muy importante de financiar las fluctuaciones inesperadas en el comercio, regular las variaciones bruscas en el tipo de cambio y en la tasa de interés, sin embargo, incrementos que superen los \$1,000 millones de dólares son exagerados y desequilibrarían la cartera óptima de activos en los que el país debe asignar sus ahorros (monetarios y no monetarios).

En vista de estas consideraciones, se optó por establecer, en lugar de la hipótesis de "patrón oro", una meta "razonable" para el incremento en las reservas internacionales y completar el crecimiento de la base monetaria mediante financiamientos al sector público. Para este efecto se consideró que las reservas internacionales deberán aumentar al mismo ritmo que el PIB nominal. Los resultados obtenidos aparecen en el siguiente cuadro.

\section{Cuadro 16}

Monetización Adecuada de Reservas Internacionales

(En miles de millones de pesos y millones de dólares a precios corrientes)

\begin{tabular}{|c|c|c|c|c|}
\hline Concepto & 1979 & 1980 & 1981 & 1982 \\
\hline 1. Incremento en la base monetaria (pesos) & 97.5 & 119.9 & 138.8 & 157.2 \\
\hline $\begin{array}{l}1.1 \text { Incremento deseado en Reservas Internacionales } \\
\text { (dólares) }\end{array}$ & 448.0 & 551.0 & 638.0 & 723.0 \\
\hline $\begin{array}{l}1.2 \text { Incremento en la base monetaria por } \\
\text { monetización de divisas (pesos) }\end{array}$ & 11.3 & 15.4 & 18.8 & 22.1 \\
\hline 1.3 Crédito al Gobierno (pesos) & 86.2 & 104.5 & 120.0 & 135.1 \\
\hline $\begin{array}{l}\text { 2. Requerimientos de entrada de capitales para } \\
\text { cubrir variación en reservas y saldo en cuenta } \\
\text { corriente (pesos) }\end{array}$ & 39.2 & 1.6 & -25.3 & -53.9 \\
\hline
\end{tabular}

* Cuadro No. 14, 4. Renglón.

* Tomado del Cuadro No. 14 
C. Política monetaria y balanza de capitales

Con base en las metas de incrementos en las reservas internacionales, que aparecen en el cuadro No. 16 podemos proceder a establecer la congruencia de la política de endeudamiento externo con la restricción monetaria.

El saldo en la cuenta corriente de la balanza de pagos se ha derivado de las proyecciones de crecimiento en la inversión y el ahorro interno que se hiciera en la primera parte de este ejercicio.

El endeudamiento externo deberá ser igual al déficit en la cuenta corriente más demanda corriente (primeras diferencias) de reservas internacionales.

En el siguiente cuadro se asientan los montos máximos de endeudamiento externo requerido (incluyendo inversión extranjera directa) necesarios para mantener en equilibrio la balanza de pagos, dadas las metas de consumo e inversión y las proyecciones de crecimiento del producto real.

\section{Cuadro 17}

Requerimientos de Entradas Netas de Capitales del Exterior

(En miles de millones)

\begin{tabular}{|c|c|c|c|c|}
\hline Concepto & 1979 & 1980 & 1981 & 1982 \\
\hline Variación deseada de reservas internacionales (pesos) & 11.3 & 15.4 & 18.8 & 22.1 \\
\hline Saldo en cuenta corriente (pesos) & -27.9 & 13.8 & 44.1 & 76.1 \\
\hline Requerimientos de entradas netas de capitales (pesos) & 39.2 & 1.6 & -25.3 & -54.0 \\
\hline $\begin{array}{l}\text { Requerimientos de entradas netas de capitales } \\
\text { (millones de dólares) }\end{array}$ & 1,549 & 57.3 & -860 & -1770 \\
\hline
\end{tabular}

Si se cubren los requerimientos de entrada neta de capitales que aparecen en el cuadro No. 17 la oferta de divisas (que es igual al saldo de cuenta corriente más la entrada neta de capitales) sería igual a la demanda corriente por reservas internacionales. Simultáneamente, la monetización de las divisas más el crédito del gobierno, cubrirían las necesidades de circulante de la economía. 
D. Impacto del sector petrolero en el mercado de divisas y de dinero

Dada la importancia y considerable impacto que la balanza de pagos de PEMEX tendrá en el mercado de divisas $\mathrm{y}$, en especial, en la dinámica de la monetización de la entrada de reservas internacionales es conveniente separar la balanza de pagos en "petrolera" y "no petrolera".

Según la Alternativa 1 de PEMEX, ${ }^{*}$ el sector petrolero registrará un superávit creciente en su cuenta corriente con el exterior durante el período 1979-1982. Si a estas cifras se le agregan las proyecciones de endeudamiento externo, se obtiene que la captación neta de divisas de PEMEX sube de \$247 millones de dólares en 1977 a más de \$8,000 millones de dólares en 1982, es decir, 32 veces. (Véase el siguiente cuadro).

\section{Cuadro 18}

Balanza de Pagos de Pemex ${ }^{*}$

(Millones de dólares corrientes)

\begin{tabular}{lrrrrrr}
\hline \multicolumn{1}{c}{ C o n c e p t o } & 1977 & 1978 & 1979 & 1980 & 1981 & 1982 \\
\hline $\begin{array}{l}\text { 1. Balanza de mercancías y } \\
\text { servicios no factoriales }\end{array}$ & -169 & 479 & 2,587 & 4,314 & 6,088 & 7,685 \\
$\begin{array}{l}\text { 2. Balanza de servicios factoriales } \\
\text { 3. Balanza de cuenta corriente }\end{array}$ & -189 & -346 & -469 & -623 & -781 & -939 \\
$\begin{array}{l}\text { 4. Endeudamiento externo neto } \\
\text { 5. Captación neta de divisas }\end{array}$ & 605 & 1,495 & 1,575 & 1,680 & 1,583 & 1,698 \\
$\begin{array}{l}\text { 6. Captación neta de divisas } \\
\text { (miles de millones de pesos) }\end{array}$ & 247 & 1,628 & 3,693 & 5,371 & 6,890 & 8,444 \\
\end{tabular}

Con base en la Alternativa 1 de PEMEX de febrero 9 de 1979.

Al transformar a pesos la balanza de pagos de PEMEX, aplicando las proyecciones de tipo de cambio que aparecen en el cuadro No. 14, resulta que la captación neta de divisas de la Institución pasa de $\$ 900,000$ millones de pesos en 1979 a $\$ 236,000$ millones de pesos en 1982 .

Las divisas, finalmente monetizadas, dependerán del superávit global de la balanza de pagos, es decir, dependen también del comportamiento del sector no petrolero.

\footnotetext{
* Hemos adoptado la Alternativa 1 como marco de referencia, lo que no implica aceptarla como la solución óptima al problema de extracción y venta de hidrocarburos.
} 
Como se puede observar en el Cuadro No. 19, el resto de la economía tendrá un déficit en cuenta corriente del sector petrolero en 1978 y 1979, pero a partir de 1980, el superávit petrolero es mayor que el déficit del sector no petrolero, lo que genera un superávit en la cuenta corriente total.

Cuadro 19

Balanza de Cuenta Corriente Desglosada en dos Sectores

(Miles de millones de pesos corrientes)

\begin{tabular}{lrrrrr}
\hline \multicolumn{1}{c}{ C o n c e p t o } & \multicolumn{1}{c}{1978} & 1979 & \multicolumn{1}{c}{1980} & \multicolumn{1}{c}{1981} & \multicolumn{1}{c}{1982} \\
\hline A. Balanza de Mercancías y Servicios no Factoriales & 9.8 & 61.4 & 118.8 & 160.8 & 206.0 \\
A.1 Sector Petrolero & 10.9 & 65.4 & 120.4 & 179.0 & 234.4 \\
A.2 Sector no Petrolero & -1.1 & -4.0 & -1.6 & -18.2 & -28.4 \\
B. Balanza de Servicios Factoriales & -63.8 & -89.3 & -104.9 & -116.7 & -129.9 \\
B.1 Sector Petrolero & -7.9 & -11.8 & -17.4 & -23.0 & -28.6 \\
B.2 Sector no Petrolero & -55.9 & -77.5 & -87.5 & -93.7 & -101.3 \\
C. Balanza de Cuenta Corriente & -54.0 & -27.9 & 13.9 & 44.1 & 76.1 \\
C.1 Sector Petrolero & 3.0 & 53.6 & 103.0 & 156.0 & 205.8 \\
C.2 Sector no Petrolero & -57.0 & -81.5 & -89.1 & -111.9 & -129.7 \\
D. Tasa de Cambio & 22.7 & 25.3 & 27.9 & 29.5 & 30.5 \\
Balanza de Cuenta Corriente (millones de dólares) & $-2,379$ & $-1,102$ & 498 & 1,495 & 2,495 \\
\hline
\end{tabular}

En el período 1981-1982, el superávit en la cuenta corriente resulta mayor que el incremento deseado en las reservas internacionales, es decir, se tiene un exceso de oferta de divisas que será necesario utilizar en el exterior para mantener la meta de crecimiento de la liquidez.

Para cumplir con la meta de monetización de reservas, resulta necesario ajustar la balanza de capitales o cambiar la apertura con el exterior y, en este último caso, modificar las estimaciones de absorción que se realizaron en la primera parte de este ejercicio.

Para iniciar el análisis de la cuenta de capital, se hacen los siguientes supuestos:

a) El endeudamiento externo neto del sector no petrolero (público y privado) se mantiene en \$1,300 millones de dólares anuales de 1979 a 1982.

b) Las cifras de endeudamiento del sector petrolero se tomaron de la Alternativa I de PEMEX.

Bajo estos supuestos se obtiene el siguiente resultado de exceso de oferta de divisas. 
Cuadro 20

Oferta y Demanda de Divisas

(Millones de dólares)

\begin{tabular}{|c|c|c|c|c|}
\hline Concepto & 1979 & 1980 & 1981 & 1982 \\
\hline A. Oferta de divisas & 1,773 & 3,476 & 4,383 & 5,491 \\
\hline A.1 Balanza en cuenta corriente & $-1,102$ & 496 & 1,500 & 2,493 \\
\hline A.2 Endeudamiento no petrolero & 1,300 & 1,300 & 1,300 & 1,300 \\
\hline A. $3 \mathrm{Er}$ & 1,575 & 1,680 & 1,583 & 1,698 \\
\hline r reservas internac & 448 & 551 & 638 & 723 \\
\hline C. Exceso de oferta de divisas $=\mathrm{A}-\mathrm{B}$ & 1,325 & 2,925 & 3,745 & 4,768 \\
\hline $\begin{array}{l}\text { D. Exceso de base monetaria (sobre el programado) } \\
\text { generado por monetización de exceso de oferta de } \\
\text { divisas (en miles de millones de pesos) }\end{array}$ & 33.5 & 81.6 & 110.1 & 145.4 \\
\hline
\end{tabular}

El impacto sobre la base monetaria resulta mayor que la meta programada para 1980 y 1982 como se muestra a continuación.

\section{Cuadro 21}

Base Monetaria y Medios de Pago

(Miles de millones de pesos)

\begin{tabular}{lrrrr}
\hline \multicolumn{1}{c}{ C o n c e p t o } & 1979 & \multicolumn{1}{c}{1980} & \multicolumn{1}{c}{1981} & 1982 \\
\hline 1. Incremento total programado en la base monetaria & 97.5 & 119.9 & 138.8 & 157.2 \\
2. Incremento en la base si se monetiza todo el exceso de divisas & 131.0 & 201.5 & 248.9 & 305.6 \\
3. Exceso de oferta monetaria & 33.5 & 81.6 & 110.1 & 145.4 \\
\hline
\end{tabular}

Por lo tanto, si se permite que el sector no petrolero se endeude en 1,300 millones de dólares al año y si se sostiene el programa de endeudamiento externo de PEMEX, en 1980 habrá un exceso de divisas de cerca de 3,000 millones de dólares, y para 1982 ascendería a más de 4,700 millones de dólares.

Bajo el escenario financiero presentado por PEMEX, los excedentes de divisas resultan en un impacto considerable sobre el medio circulante y, por lo tanto, será necesario eliminarlo, para lo cual se analizan a continuación las siguientes opciones: 

a) Un aumento en la emisión de CETES.
b) Disminuir el crédito del Banco Central al gobierno.
c) Aumentar los niveles de absorción (consumo más inversión).
d) Aumentar las salidas netas de capital del sector no petrolero.

Aún suponiendo que fuera posible una emisión de CETES de tal magnitud, la primera opción implica aceptar un desmesurado incremento en las reservas internacionales que nos parece fuera de un equilibrio conveniente en la distribución de la cartera nacional entre inversión física y financiera. Una mayor "inversión financiera" en reservas internacionales se justificaría si el rendimiento de la misma (en términos mayores márgenes de seguridad) es mayor que el rendimiento alternativo que consiste en el ahorro de los intereses sobre la deuda externa ( $(12 \%$ ?) o de rendimientos marginales obtenidos por adiciones al acervo de capital del país (¿15\%?).

La segunda opción que consiste en disminuir el crédito al gobierno para permitir una mayor monetización vía reservas internacionales, implica disminuir el uso que el sector público hace del ahorro monetario (señoreaje de la moneda más impuesto inflacionario) para transferirlo a "inversión" en reservas internacionales. Para justificar esta opción sería necesario que los rendimientos de la inversión pública fueran sumamente bajos o negativos, tanto que resultaron inferiores a la rentabilidad implícita en el incremento de las reservas internacionales. Esto supone que las otras fuentes de financiamiento (encaje, deuda externa y ahorro corriente), se mantienen constantes, pues, de esta forma, una disminución en el crédito al gobierno implica una disminución en el crédito al gobierno implica una disminución en la inversión.

La tercera opción que consiste en promover incrementos en la absorción, parece razonable si es posible aumentar la inversión real con un rendimiento social mayor que el ahorro de intereses obtenido al disminuir el endeudamiento externo. Para ello, se deben tomar en cuenta las limitaciones que actúan sobre la inversión, tales como los cuellos de botella en los recursos domésticos (transportes, cemento, mano de obra calificada, etc.). Un aumento en la absorción vía mayor consumo resulta equivalente a sustituir más ahorro externo por menos ahorro doméstico, y viola el principio de conservación de la riqueza total que se ha estado siguiendo. 
Introducir mayores niveles de absorción implica revisar la estrategia planteada en la primera parte de este ejercicio y sería tema para un nuevo documento. Sin embargo, a continuación discutimos las ventajas y desventajas de algunas opciones para aumentar la absorción.

1) Una inflación doméstica mayor que la extranjera.

2) Revaluar el peso

3) Liberalizar el comercio exterior

La primera medida implica una sobrevaluación cambiaria que desalentaría las exportaciones no petroleras y tendría un efecto negativo sobre el empleo.

La revaluación del peso tendría el mismo efecto sobre el empleo que la sobrevaluación pero de manera más rápida pues afectaría igualmente a las exportaciones no petroleras y en particular; a las que no reciben subsidios (tales como el turismo).

La liberalización del comercio resulta ser una medida menos perjudicial porque no involucra un sesgo antiexportador y por tanto antiempleo, pero su instrumentación no asegura mayores niveles de inversión en el corto plazo.

Enseguida analizamos la cuarta opción para eliminar el exceso de oferta monetaria que se presenta por la monetización del exceso de divisas y que consiste en aumentar las Salidas Netas de Capital del sector no petrolero, si el endeudamiento programado de PEMEX se lleva a cabo.

Con esta opción, para cumplir con la meta de inflación, sería necesario reducir el endeudamiento externo del sector no petrolero como enseguida se describe: 


\section{Cuadro 22}

Endeudamiento Externo Neto del Sector no Petrolero

(En millones de dólares)

\begin{tabular}{lrrrr}
\hline \multicolumn{1}{c}{ C o n c e p to } & 1979 & 1980 & \multicolumn{1}{c}{1981} & \multicolumn{1}{c}{1982} \\
\hline Requerimientos totales de Endeudamiento externo. & 1,549 & 57.3 & -860 & $-1,767$ \\
Endeudamiento de PEMEX & 1,575 & 1,680 & 1,583 & 1,698 \\
Endeudamiento del sector no petrolero & -26 & $-1,623$ & $-2,443$ & $-3,465$ \\
\hline
\end{tabular}

* Del cuadro No. 17

La reducción en el endeudamiento externo neto se podría conseguir mediante:

1) Un adelanto del pago de la deuda del sector público no petrolero.

2) Una salida de capitales del sector privado.

El adelanto del pago de la deuda pública no petrolera carece de sentido si por otro lado se está incrementando simultáneamente la deuda del sector petrolero.

Por otro lado, la fuga de capitales del sector privado resulta poco probable y menos razonable en el contexto de estabilidad de precios y de tasas de interés internas positivas y competitivas en términos reales, que son requisito para que el sector financiero cumpla adecuadamente sus funciones de intermediación. Aún si las tasas de interés domésticas bajaran, esto no asegura la salida de capitales si, debido al exceso de oferta de divisas, se han generado expectativas de revaluación cambiaria.

Finalmente, para eliminar el exceso de oferta de dinero, queda la opción más atractiva de incrementar el financiamiento global del déficit de PEMEX mediante una mayor generación de ahorro interno, sustituyendo su endeudamiento externo.

Lo anterior puede lograrse a través de:

a) Un incremento en los precios domésticos de los productos petroleros y mejorar la productividad de la empresa.

b) Un incremento en el financiamiento interno hacia el sector petrolero. 
Con respecto al incremento en los precios domésticos de los productos petroleros, la medida permitiría, además de aminorar el problema financiero, una mayor eficiencia en el uso interno de los energéticos.

La segunda opción puede lograrse a través de incrementos en la emisión de valores en el mercado abierto y un mayor financiamiento del sistema bancario canalizado a través del Banco Central o de Instituciones de Crédito.

E. La transferencia de ahorros y requerimientos de intermediación financiera.

La absorción de bienes de consumo y la inversión programada para el país en los próximos años, está limitada por la capacidad de la economía para invertir productivamente (desde el punto de vista social) más allá de su tendencia histórica, con el fin de transformar la riqueza petrolera exportada en otras fuentes de ingreso permanente.

Existen restricciones de orden interno a dicha capacidad sobretodo en los próximos dos años, lo que plantea la necesidad de programar el crecimiento de las inversiones el mismo ritmo en que se suavicen dichas restricciones.

Aumentar el consumo por encima del monto proyectado implicaría elevar la deuda externa del presente y pagarla con los excedentes petroleros del futuro, esto es, se compromete parte de la actual riqueza petrolera.

Las limitaciones antes mencionadas ayudan a explicar los bajos niveles de ahorro externo (cuenta corriente de la balanza de pagos) que se proyectan en el presente ejercicio, lo que nos obliga a incrementar el ahorro doméstico (público más privado). Sin embargo, debido al incremento del ahorro público, los requerimientos sobre el ahorro privado aumentarán sólo ligeramente.

El ahorro del sector público, como porcentaje del PIB, pasará de $2.5 \%$ en 1978 a $6.6 \%$ en 1982, y el ahorro privado requerido pasará de $20.4 \%$ en 1978 a 20.3\% en 1982 . (Véase cuadro básico). 
En resumen, en el financiamiento de la inversión nacional:

a) Bajará la participación del ahorro externo.

b) Aumentará la del ahorro público.

c) La participación del ahorro privado se mantendrá constante.

En particular, la inversión pública será financiada en mayor proporción con ahorros propios y en menos proporción con ahorro externo, requiriendo una transferencia menor de ahorros privados.

En el cuadro No. 23 se proyectan las necesidades de financiamiento interno del sector público.

\section{Cuadro 23}

Transferencia de Ahorros y Requerimientos de Ahorros Financieros

(Miles de millones de pesos a precios corrientes)

\begin{tabular}{|c|c|c|c|c|}
\hline Concepto & 1979 & 1980 & 1981 & 1982 \\
\hline 1. Ahorro privado total $\stackrel{1 /}{ }$ & 525.7 & 665.4 & 843.5 & $1,027.5$ \\
\hline 2. Inversión privada ${ }^{1 /}$ & 361.3 & 465.1 & 623.3 & 790.5 \\
\hline 3. PIB nominal $\underline{1 /}$ & $2,648.8$ & $3,345.4$ & $4,151.7$ & $5,065.1$ \\
\hline 4. Requerimientos de financiamiento & 248.7 & 321.4 & 394.7 & \\
\hline 4.1 Privado $\stackrel{2 /}{ }$ & 93.9 & 125.6 & 174.5 & 229.6 \\
\hline 4.2 Público $\stackrel{3 /}{2}$ & 154.58 & 195.8 & 220.2 & 236.8 \\
\hline 4.2.1. Requerimientos del sector público como $\%$ del PIB & 5.8 & 5.8 & 5.3 & 4.7 \\
\hline $\begin{array}{l}\text { 4.2.2. Requerimientos del sector público como } \% \text { del } \\
\text { ahorro privado }\end{array}$ & 29.4 & 29.4 & 26.1 & 23.0 \\
\hline $\begin{array}{l}\text { 5. Proyección de ahorros financieros monetarios y no } \\
\text { monetarios }\end{array}$ & 241.4 & 316.4 & 409.5 & 529.6 \\
\hline 5.1 Ahorros financieros no monetarios $\stackrel{4 /}{-}$ & 171.2 & 230.3 & 309.6 & 416.4 \\
\hline 5.2 Ahorro monetario $\stackrel{5 /}{-}$ & 70.2 & 86.3 & 99.9 & 113.2 \\
\hline 6. Indice de exceso de oferta de ahorros $(6=5 / 4)$ & 0.97 & 0.98 & 1.04 & 1.14 \\
\hline
\end{tabular}

1/ Tomado del cuadro básico y multiplicado por el índice de precios que aparece en el mismo cuadro.

2/ Se estimó que el coeficiente de requerimientos financieros era igual a $26 \%$ de la inversión privada en 1979 y aumenta en un punto porcentual cada año. La inversión privada se derivó del cuadro básico.

3/ Los requerimientos de financiamiento del sector público se obtuvieron de restar de la inversión pública el ahorro público y el ahorro externo que aparece en el cuadro básico y el financiamiento por incremento en ADEFAS.

4/ Como se explica en el texto se estimó en base a una elasticidad ingreso de 2.255

5/ El ahorro monetario es igual al incremento en la demanda de dinero que se estimó en el cuadro \#14. 
Dicha transferencia pasará de un $29.4 \%$ en 1979 a un $23.0 \%$ en 1982 , como porcentaje del ahorro privado.

El renglón cuarto del mismo cuadro nos muestra los requerimientos del ahorro financiero que tendrá la economía en los próximos años. Este rubro se obtiene como la suma del endeudamiento interno del sector público (renglón 4.2) más los requerimientos de financiamiento de la inversión privada, (renglón 4.1). Por otro lado, el endeudamiento interno del sector público se obtiene de restar el ahorro público, el ahorro externo y el financiamiento por incremento en ADEFAS, de la inversión pública.

Se estima que los requerimientos de financiamiento de la inversión privada pasarán de un $25 \%$ en 1978 a un $29 \%$ en 1982 . Esto significa un crecimiento promedio en el crédito al sector privado de alrededor de $30 \%$ anual en términos nominales.

En el renglón cinco del mismo cuadro 23 de describen las proyecciones de ahorro financiero monetario y no monetario, es decir, un incremento en la demanda de dinero y de activos financieros.

Para realizar las proyecciones de ahorro financiero no monetario, se llevó a cabo una regresión, haciéndolo función de:
a) El ingreso permanente,
b) Diferenciales de tasas de interés y
c) Expectativas de inflación. *

\footnotetext{
* Se supone que el ahorro externo sólo financia al sector público

- $\quad$ El ajuste obtenido fue el siguiente:

$$
\begin{aligned}
& \text { Ln } \mathrm{A}=-16.94+2.255 \text { Ln } \mathrm{Y}-0.012 \text { Ln } \mathrm{D}-0.055 \text { Ln } \mathrm{P} \\
& \text { (21.03) } \quad(-1.73) \quad(-2.42)
\end{aligned}
$$

donde:

$L n=$ Logaritmo natural.

$A=$ Activos financieros no monetarios en términos reales.

$Y=$ Indice de ingreso permanente obtenido mediante una interpolación del PIB en términos reales.

$D=\mathrm{i} *-\mathrm{i}$

$i=$ Tasa doméstica de interés nominal pasiva y promedio ponderado de los principales instrumentos.

$i^{*}=$ Tasa de interés doméstica de equilibrio según la teoría de la paridad de las tasas de interés.

$P=$ Expectativas de inflación
} 
donde:

$S=$ Tasa spot pesos/dólares.

$F=$ Tasa de futuros pesos/dólares.

$e=$ Tasa de interés extranjera.

La regresión se corrió con datos mensuales para el período 1973-1978 y arrojó una elasticidad ingreso de 2.255. Los coeficientes de diferenciales de tasas de interés y de expectativas de inflación resultaron con el signo correcto y el valor de " $\mathrm{t}$ " nos indica que son estadísticamente significativos. Se obtuvo un coeficiente de correlación múltiple de 0.98 .

Las proyecciones de ahorro financiero no monetario se hicieron bajo el supuesto de que las tasas de interés y las expectativas de inflación se mantendrían al mismo nivel que tuvieron en 1978, es decir, sólo se consideró el efecto del crecimiento del PIB real sobre la captación.

Como puede observarse en el renglón 6 del mismo cuadro No. 23, el período 1979-80 muestra un exceso de demanda de fondos prestables y en 1981-82 éste se traduce en un exceso de oferta de fondos prestables.

El desequilibrio en el mercado financiero puede ser eliminado permitiendo:

a) Que el mercado financiero ajuste, por medio de cambios en la tasa de interés, cualquier desequilibrio entre la oferta y la demanda de fondos prestables. Con esto continuaría manteniéndose en equilibrio el resto de los mercados.

b) Cambiar el encaje legal para afectar el uso de ahorros financieros que con fines de consumo o inversión, hace el sector privado.

$$
i^{*}=(F / S)(1+\mathrm{e})-1
$$


c) Que el desequilibrio financiero se refleje en el mercado de bienes y servicios. De esta forma se afectarían los saldos en cuenta corriente y de capital, conservando constante la meta de reservas internacionales.

d) Dejando constante el grado de apertura con el exterior que el ajuste se realice en el mercado monetario mediante tasas de inflación diferentes a las programadas.

e) Cambiar simultáneamente el endeudamiento público y la meta de incremento en reservas internacionales. Con esto se mantiene el equilibrio en el mercado de divisas.

El análisis de cada una de estas opciones y en particular de los mecanismos de transmisión del desequilibrio a otros mercados, merecen especial atención por lo que se discutirán en un documento posterior. 


\section{APENDICE 1}

\section{Cuadro Básico}

Ejercicio Macroeconómico de Dos Sectores: Petrolero y No Petrolero

(Miles de Millones de Pesos de 1972)

\begin{tabular}{|c|c|c|c|c|c|c|c|}
\hline & Concepto & 1977 & 1978 & 1979 & 1980 & 1981 & 1982 \\
\hline$\overline{\mathrm{A}}$ & Inversión Fija Bruta & 129.1 & 152.5 & 165.0 & 181.1 & 199.9 & 215.8 \\
\hline A.1 & Inversión Fija Bruta Sector Petrolero & 13.5 & 20.6 & 22.7 & 26.1 & 25.2 & 24.5 \\
\hline A. 2 & Inversión Fija Bruta resto de la economía & 115.6 & 131.9 & 142.3 & 155.0 & 174.7 & 191.3 \\
\hline A. 3 & Inversión Fija Bruta Sector Petrolero/IFB total (\%) & 10.5 & 13.5 & 13.8 & 14.4 & 12.6 & 11.7 \\
\hline B & Variación de Inventarios & 25.7 & 20.3 & 18.3 & 19.9 & 21.6 & 23.6 \\
\hline $\mathrm{C}$ & Inversión Brutal total $(\mathrm{A}+\mathrm{B})$ & 154.8 & 172.8 & 183.3 & 201.0 & 220.6 & 239.4 \\
\hline $\mathrm{D}$ & Producto Interno Bruto & 637.7 & 677.2 & 730.0 & 795.0 & 865.8 & 942.9 \\
\hline D.1 & PIB Sector Petrolero & 20.4 & 26.0 & 38.1 & 50.6 & 55.7 & 59.8 \\
\hline D.2 & PIB resto de la economía & 617.3 & 651.2 & 691.9 & 744.4 & 810.1 & 833.1 \\
\hline $\mathrm{E}$ & Consumo Total & 480.5 & 501.2 & 529.8 & 565.8 & 611.6 & 665.1 \\
\hline $\mathrm{F}$ & Balanza de Mercancías y Servicios & -13.3 & -17.5 & -7.7 & 3.3 & 9.2 & 14.2 \\
\hline F.1 & Balanza de Mercancías y Servicios Sector Petrolero & -3.1 & 1.0 & 14.8 & 24.5 & 32.6 & 38.4 \\
\hline F.2 & Balanza de Mercancías y Servicios resto de la economía & -10.2 & -18.5 & -22.5 & -21.2 & -23.4 & -24.2 \\
\hline G & Ahorro externo (incluyendo variación en reservas internacionales) & 13.3 & 17.5 & 11.8 & -0.2 & -5.5 & -9.9 \\
\hline G.1 & Ahorro externo (sin variación en reservas internacionales) & 13.3 & 17.5 & 7.7 & -3.3 & -9.2 & -14.2 \\
\hline G.2 & Variación en reservas internacionales & -- & -- & 4.1 & 3.1 & 3.7 & 4.3 \\
\hline $\mathrm{H}$ & Ahorro del sector público & 6.3 & 16.6 & 30.7 & 46.2 & 54.0 & 62.4 \\
\hline H.1 & Ahorro del sector petrolero & 14.3 & 18.7 & 30.0 & 41.9 & 46.2 & 49.9 \\
\hline H.2 & Ahorro del resto del sector público & -8.0 & -2.1 & 0.7 & 4.3 & 7.8 & 12.5 \\
\hline H.3 & Ahorro Sector petrolero/Ahorro sector público (\%) & 227.0 & 112.7 & 97.7 & 90.7 & 85.6 & 80.0 \\
\hline I & Ahorro privado & 135.2 & 138.7 & 144.9 & 158.1 & 175.8 & 191.2 \\
\hline $\mathrm{J}$ & Inversión pública - ahorro público & 49.9 & 59.3 & 53.0 & 44.3 & 36.7 & 29.9 \\
\hline $\mathrm{K}$ & $\%$ en el empleo & -- & 3.7 & 3.9 & 4.0 & 4.0 & 4.0 \\
\hline $\mathrm{L}$ & Tipo de cambio (pesos/dólar) & 22.6 & 22.7 & 25.3 & 27.9 & 29.5 & 30.5 \\
\hline M & Deflactor & 2.628 & 3.075 & 3.628 & 4.209 & 4.798 & 5.374 \\
\hline
\end{tabular}




\section{APENDICE 1}

\section{Cuadro Básico}

Ejercicio Macroeconómico de Dos Sectores: Petrolero y No Petrolero

(Tasas de Crecimiento)

\begin{tabular}{|c|c|c|c|c|c|c|c|}
\hline & Concepto & 1977 & 1978 & 1979 & 1980 & 1981 & 1982 \\
\hline$\overline{\mathrm{A}}$ & Inversión Fija Bruta & & 18.1 & 8.2 & 9.8 & 9.9 & $\overline{8.4}$ \\
\hline A. 1 & Inversión Fija Bruta Sector Petrolero & & 52.6 & 10.2 & 15.0 & -3.4 & -2.8 \\
\hline A. 2 & Inversión Fija Bruta resto de la economía & & 14.1 & 7.9 & 8.9 & 12.7 & 9.5 \\
\hline A. 3 & Inversión Fija Bruta Sector Petrolero/IFB total (\%) & & - & - & - & - & - \\
\hline $\mathrm{B}$ & Variación de Inventarios & & -21.0 & -9.9 & 8.7 & 8.5 & 9.3 \\
\hline $\mathrm{C}$ & Inversión Brutal total $(\mathrm{A}+\mathrm{B})$ & & 11.6 & 6.1 & 9.7 & 9.8 & 8.5 \\
\hline $\mathrm{D}$ & Producto Interno Bruto & 3.2 & 6.2 & 7.8 & 8.9 & 8.9 & 8.9 \\
\hline D. 1 & PIB Sector Petrolero & & 27.5 & 46.5 & 32.8 & 10.1 & 7.4 \\
\hline D. 2 & PIB resto de la economía & & 5.5 & 6.3 & 7.6 & 8.8 & 9.0 \\
\hline $\mathrm{E}$ & Consumo Total & & 4.3 & 5.7 & 6.8 & 8.1 & 8.7 \\
\hline $\mathrm{F}$ & Balanza de Mercancías y Servicios & & - & - & - & - & - \\
\hline F.1 & Balanza de Mercancías y Servicios Sector Petrolero & & - & - & - & - & - \\
\hline F.2 & Balanza de Mercancías y Servicios resto de la economía & & - & - & - & - & - \\
\hline $\mathrm{G}$ & Ahorro externo (incluyendo variación en reservas I) & & - & - & - & - & - \\
\hline G.1 & Ahorro externo (sin variación en reservas internacionales) & & - & - & - & - & - \\
\hline G.2 & Variación en reservas internacionales & & - & - & - & - & - \\
\hline $\mathrm{H}$ & Ahorro del sector Público & & 163.5 & 84.4 & 50.5 & 16.7 & 15.6 \\
\hline H.1 & Ahorro del sector Petrolero & & 30.8 & 60.4 & 39.7 & 10.3 & 8.0 \\
\hline H.2 & Ahorro del resto del Sector público & & 73.8 & 128.6 & 514.3 & 81.4 & 60.3 \\
\hline H.3 & Ahorro Sector petrolero/Ahorro sector público (\%) & & - & - & - & - & - \\
\hline I & Ahorro Privado & & 2.6 & 4.5 & 9.1 & 11.2 & 8.8 \\
\hline $\mathrm{J}$ & Inversión Pública - Ahorro Público & & 18.8 & -10.6 & -16.4 & -17.2 & -18.5 \\
\hline $\mathrm{K}$ & $\%$ en el empleo & & - & - & - & - & - \\
\hline $\mathrm{L}$ & Tipo de cambio (pesos/dólar) & & - & - & - & - & - \\
\hline M & Deflactor & & 17.0 & 14.0 & 12.0 & 12.0 & 12.0 \\
\hline
\end{tabular}




\section{APENDICE 1}

Cuadro Básico

Ejercicio Macroeconómico de Dos Sectores: Petrolero y No Petrolero

(Como \% del PIB)

\begin{tabular}{|c|c|c|c|c|c|c|c|}
\hline & Concepto & 1977 & 1978 & 1979 & 1980 & 1981 & 1982 \\
\hline A & Inversión Fija Bruta & 20.3 & 22.5 & 22.5 & 22.8 & 23.0 & 22.9 \\
\hline A. 1 & Inversión Fija Bruta Sector Petrolero & 2.1 & 3.0 & 3.1 & 2.3 & 2.9 & 2.6 \\
\hline A. 2 & Inversión Fija Bruta resto de la economía & 18.2 & 19.5 & 19.5 & 19.5 & 20.2 & 20.3 \\
\hline A. 3 & Inversión Fija Bruta Sector Petrolero/IFB total (\%) & - & - & - & - & - & - \\
\hline B & Variación de Inventarios & 4.0 & 3.0 & 2.5 & 2.5 & 2.5 & 2.5 \\
\hline $\mathrm{C}$ & Inversión Brutal total $(\mathrm{A}+\mathrm{B})$ & 24.0 & 25.5 & 25.1 & 25.3 & 25.5 & 25.4 \\
\hline $\mathrm{D}$ & Producto Interno Bruto & 100.0 & 100.0 & 100.0 & 100.0 & 100.0 & 100.0 \\
\hline D. 1 & PIB Sector Petrolero & 3.2 & 3.8 & 5.2 & 6.4 & 6.4 & 6.3 \\
\hline D. 2 & PIB resto de la economía & 96.8 & 96.2 & 94.8 & 93.6 & 93.6 & 93.7 \\
\hline $\mathrm{E}$ & Consumo Total & 75.3 & 74.0 & 72.6 & 71.2 & 70.6 & 70.5 \\
\hline $\mathrm{F}$ & Balanza de Mercancías y Servicios & -2.1 & -2.6 & -1.1 & 0.4 & 1.1 & 1.5 \\
\hline F.1 & Balanza de Mercancías y Servicios Sector Petrolero & -0.5 & 0.1 & 2.0 & 3.1 & 3.8 & 4.1 \\
\hline F.2 & Balanza de Mercancías y Servicios resto de la economía & -1.6 & -2.7 & -3.1 & -2.7 & -2.7 & -2.6 \\
\hline G & Ahorro externo (incluyendo variación en reservas I) & -2.1 & -2.6 & 1.6 & 0.0 & -0.6 & 1.0 \\
\hline G.1 & Ahorro externo (sin variación en reservas internacionales) & 2.1 & 2.6 & 1.1 & -0.4 & -1.1 & -1.5 \\
\hline G.2 & Variación en reservas internacionales & - & - & 0.5 & 0.4 & 0.5 & 0.5 \\
\hline $\mathrm{H}$ & Ahorro del sector Público & 0.9 & 2.5 & 4.2 & 5.8 & 6.2 & 6.6 \\
\hline H.1 & Ahorro del sector Petrolero & 2.2 & 2.7 & 1.1 & 5.3 & 5.3 & 5.3 \\
\hline H.2 & Ahorro del resto del sector público & -1.3 & -0.2 & 0.1 & 0.5 & 0.9 & 1.3 \\
\hline H.3 & Ahorro Sector petrolero/Ahorro sector público (\%) & - & - & - & - & - & - \\
\hline I & Ahorro Privado & 21.2 & 20.2 & 19.5 & 19.8 & 20.3 & 20.4 \\
\hline $\mathrm{J}$ & Inversión Pública - Ahorro Público & 7.8 & 8.7 & 7.3 & 5.6 & 4.2 & 3.2 \\
\hline K & $\%$ en el empleo & - & - & - & - & - & - \\
\hline $\mathrm{L}$ & Tipo de cambio (pesos/dólar) & - & - & - & - & - & - \\
\hline M & Deflactor & - & - & - & - & - & - \\
\hline
\end{tabular}




\section{APENDICE 2}

Cálculo de Valor Agregado por Pemex

1. Los ingresos por exportaciones de la alternativa 1 de PEMEX fueron ajustados por dos factores:

a) Corrección por precios. Debido a que en el documento de PEMEX se supone que los precios del crudo en el exterior no cambian en 1979 y de hecho ya se incrementaron en $7 \%, y$

b) Corrección por tipo de cambio: se usa un tipo de cambio que conserva la paridad del poder de compra.

2. Los ingresos provenientes de las ventas internas y otros ingresos corrientes los tomamos tal como aparecen en la alternativa 1 de PEMEX.

3. Para determinar los insumos intermedios de PEMEX, del renglón de gastos de operación dedujimos los pagos por sueldos y salarios, los que a su vez los estimamos de la siguiente manera:

$$
W_{t}=\mathrm{N}_{\mathrm{o}}\left(1+\mathrm{N}_{\mathrm{t}}\right) \mathrm{W}_{\mathrm{o}}\left(1+\mathrm{P}_{\mathrm{t}}\right)
$$

donde:

$W_{t}=$ Total de sueldos y salarios en el año $t$.

$N_{o}=$ Personal ocupado en 1977.

$N_{t}=$ Tasa de crecimiento en el número de empleados de PEMEX de acuerdo a los datos de la SPP presentados en "Bases del Plan Global de Desarrollo 1978-1979”.

$W_{o}=$ Sueldos y salarios promedio por trabajador en 1977. 


$$
P_{t}=\text { La tasa de inflación doméstica proyectada para el año } t \text {. }
$$

4. Los diferentes renglones de ingresos y gastos, fueron deflactados con el índice de precios domésticos que es utilizado por PEMEX.

5. El Valor Agregado Bruto de PEMEX es igual a ingresos propios menos gastos en insumos intermedios. Los ingresos y el Valor Agregado Bruto de PEMEX están especificados en los cuadros Nos. 1 y 2 de este apéndice.

\section{Cuadro 1}

Ingresos y Valor Agregado por Pemex

(Miles de millones de pesos de 1977)

\begin{tabular}{|c|c|c|c|c|c|c|}
\hline Concepto & 1977 & 1978 & 1979 & 1980 & 1981 & 1982 \\
\hline Recursos Propios ${ }^{\text {II }}$ & 88.5 & 100.7 & $\underline{126.0}$ & 160.1 & 174.2 & $\underline{185.0}$ \\
\hline Ventas Internas & 49.6 & 51.6 & 50.4 & 51.4 & 50.3 & 48.1 \\
\hline Ventas Externas & 19.1 & 38.1 & 71.0 & 104.3 & 119.5 & 132.5 \\
\hline Otros Ingresos & 19.8 & 11.0 & 4.6 & 4.4 & 4.4 & 4.4 \\
\hline Egresos $1 /$ & $\underline{69.8}$ & 75.4 & $\underline{87.7}$ & 102.0 & $\underline{107.9}$ & $\underline{112.5}$ \\
\hline Operación & 33.3 & $\overline{36.1}$ & 35.8 & 37.3 & 39.0 & 39.4 \\
\hline Imp. Federales & 18.9 & 23.9 & 40.6 & 52.0 & 55.2 & 58.6 \\
\hline Intereses & 4.3 & 6.7 & 7.9 & 9.2 & 10.2 & 10.8 \\
\hline Otro & 13.3 & 8.8 & 3.3 & 3.5 & 3.5 & 3.7 \\
\hline Ahorro Corriente ante & 37.6 & 49.2 & 78.9 & 110.1 & 121.5 & 131.1 \\
\hline Ahorro Corriente después de Impuestos & 18.7 & 25.3 & 38.3 & 58.1 & 66.3 & 72.5 \\
\hline Excedente ${ }^{2 /}$ & & 15.2 & 35.5 & 62.6 & 71.7 & 79.5 \\
\hline
\end{tabular}

1/ Cifras determinadas con base en el programa de Pemex de feb. De 1979, realizando ajuste en ventas externas a partir de 1979, por precio y por tipo de cambio de alternativa I.

2/ Calculado suponiendo que el costo total sobre precio de venta es de $60 \%$ en $1978,50 \%$ en 1979 y $40 \&$ en años subsecuentes (y referido únicamente a exportaciones). 
Cuadro 2

Ingresos y Egresos de Pemex

(Cifras en miles de millones de pesos de 1977)

\begin{tabular}{|c|c|c|c|c|c|c|}
\hline CONCEPTO & 1977 & 1978 & 1979 & 1980 & 1981 & 1982 \\
\hline$\overline{\text { INGRESOS }}$ & 88.5 & 100.7 & 126.0 & 160.1 & 174.2 & 185.0 \\
\hline GASTOS DE OPERACION MENOS SUELDOS Y SALARIOS & 35.0 & 32.3 & 25.9 & 27.0 & 27.9 & 27.8 \\
\hline VALOR AGREGADO BRUTO & $\underline{53.5}$ & 68.4 & 100.1 & 133.1 & 146.3 & 157.2 \\
\hline SUELDOS Y SALARIOS $\stackrel{1 /}{ }$ & 11.6 & 12.6 & 13.2 & 13.8 & 14.6 & 15.3 \\
\hline INTERESES & 4.3 & 6.7 & 7.9 & 9.4 & 10.6 & 11.2 \\
\hline IMPUESTOS FEDERALES & 18.9 & 23.9 & 40.6 & 52.5 & 57.1 & 63.0 \\
\hline SUPERAVIT DE OPERACIÓN & 18.7 & 25.2 & 38.4 & 57.4 & 64.0 & 67.7 \\
\hline
\end{tabular}

1/ Los sueldos y salarios fueron calculados adoptando las cifras de empleo en el sector especificado por la SPP en su Plan Global de Desarrollo 1978 y 1982 y considerando que los sueldos promedio Tendrán incrementos nominales para mantener los salarios reales promedio por trabajador constante. 


\section{APENDICE 3}

\section{Ahorro Bruto del Sector Público}

1. Con el cuadro de flujos de efectivo de PEMEX, presentando como la alternativa 1, y ajustados los ingresos por exportación con nuestra tasa de cambio, se obtuvo el ahorro de PEMEX.

2. Como puede observarse en el cuadro 3 de este apéndice, para la estimación de los ingresos y gastos de otras empresas públicas se tomó como punto de partida el cuadro 5.29 del estudio del Banco Mundial de diciembre de 1977.

3. Los ingresos y egresos corrientes del resto del sector público fueron también proyectados con base en las estimaciones que el Banco Mundial hizo de las proporciones del gasto e ingreso corrientes, respecto al PIB (véase cuadro 4 de este apéndice).

\section{Cuadro 3}

Ingresos y Egresos de Pemex ${ }^{1 /}$ y Otras Empresas Controladas Presupuestalmente ${ }^{2 /}$

(Miles de millones de pesos de 1972)

\begin{tabular}{|c|c|c|c|c|c|c|}
\hline Concepto & 1977 & 1978 & 1979 & 1980 & 1981 & 1982 \\
\hline PEMEX & & & & & & \\
\hline Ingresos & 33.7 & $\underline{38.3}$ & $\underline{47.9}$ & $\underline{60.9}$ & $\underline{66.3}$ & 70.4 \\
\hline Ventas Internas & 18.9 & 19.6 & 19.2 & 19.6 & 19.1 & 18.3 \\
\hline Ventas Externas & 7.3 & 14.5 & 27.0 & 39.7 & 45.5 & 50.4 \\
\hline Otros Ingresos & 7.5 & 4.2 & 1.7 & 1.7 & 1.7 & 1.7 \\
\hline EGRESOS & $\underline{26.6}$ & 28.7 & $\underline{33.3}$ & $\underline{38.8}$ & $\underline{41.1}$ & 42.8 \\
\hline Operación & $\overline{12.7}$ & $\overline{13.7}$ & $\overline{13.6}$ & $\overline{14.2}$ & $\overline{14.9}$ & $\overline{15.0}$ \\
\hline Impuestos Federales & 7.2 & 9.1 & 15.4 & 19.8 & 21.0 & 22.3 \\
\hline Intereses & 1.6 & 2.5 & 3.0 & 3.5 & 3.9 & 4.1 \\
\hline Otros Gastos & 5.1 & 3.4 & 1.3 & 1.3 & 1.3 & 1.4 \\
\hline AHORRO CORRIENTE ANTES IMP. & 14.3 & 18.7 & 30.0 & 41.9 & 46.2 & 49.9 \\
\hline AHORRO CORRIENTE DESPUES IMP. & 7.1 & 9.6 & 14.6 & 22.1 & 25.2 & 27.6 \\
\hline EXCEDENTE & --- & 5.8 & 13.5 & 23.8 & 27.3 & 30.3 \\
\hline OTRAS EMPRESAS & & & & & & \\
\hline Ingresos Corrientes & 30.8 & 34.1 & 37.3 & 40.7 & 44.9 & 48.1 \\
\hline Gastos Corrientes & 41.9 & 43.6 & 46.1 & 49.1 & 51.8 & 53.5 \\
\hline Ahorro Corriente & -11.1 & -9.5 & -8.8 & -8.4 & -6.9 & -5.4 \\
\hline AHORRO TOTAL & 3.2 & 9.2 & 21.2 & 33.5 & 39.3 & 44.5 \\
\hline
\end{tabular}


Cuadro 4

Cuenta Corriente del Sector Público Consolidado ${ }^{1 /}$

(Miles de millones de pesos de 1972)

\begin{tabular}{lccccccc}
\hline & Concepto & 1977 & 1978 & 1979 & 1980 & 1981 & 1982 \\
\hline 1. & Ingresos corrientes & 94.3 & 110.7 & 133.6 & 159.9 & 179.5 & 201.9 \\
a) & Impuestos & 62.5 & 70.4 & 78.8 & 89.8 & 100.4 & 114.1 \\
b) & Seguridad social & 12.7 & 13.5 & 14.6 & 15.9 & 17.3 & 18.8 \\
c) & Otros ingresos & 15.9 & 17.6 & 19.0 & 20.7 & 22.5 & 24.5 \\
d) & Ahorro de empresas públicas & 3.2 & 9.2 & 21.2 & 33.5 & 39.3 & 44.5 \\
2. Gastos Corriente & $\underline{88.0}$ & $\underline{94.1}$ & $\underline{102.9}$ & $\underline{113.7}$ & $\underline{125.5}$ & $\underline{139.5}$ \\
3. & Ahorro Corriente & $\underline{6.3}$ & $\underline{16.6}$ & $\underline{\underline{30.7}}$ & $\underline{46.2}$ & $\underline{54.0}$ & $\underline{62.4}$ \\
\hline
\end{tabular}

Cuadro 5

Exportaciones de Pemex

\begin{tabular}{lcccccc}
\hline \multicolumn{1}{c}{ CONCEPTO } & 1977 & 1978 & 1979 & 1980 & 1981 & 1982 \\
\hline Exportaciones netas (millones de dólares) & 666 & 1719 & 3675 & 5947 & 7456 & 9136 \\
$\left(P / p^{2}\right)$ & 1.00 & 1.00 & 1.07 & 1.04 & 1.04 & 1.03 \\
Exp. Netos (millones de dólares) & 666 & 1719 & 3932.3 & 6185.0 & 7754.2 & 9410.1 \\
Tipo de cambio & 22.6 & 22.7 & 24.4 & 26.0 & 27.0 & 28.0 \\
Exp. Netas (miles de millones de pesos) & 15.1 & 39.0 & 95.9 & 160.8 & 209.4 & 263.5 \\
Deflactor de PEMEX & 1.000 & 1.173 & 1.351 & 1.542 & 1.753 & 1.988 \\
Exp. Neto (miles de millones de pesos de 1977) & 15.1 & 33.2 & 71.0 & 104.3 & 119.5 & 132.5 \\
\hline
\end{tabular}




\section{APENDICE 4}

\section{Proyecciones de Consumo Total}

La proyección de consumo se realizó con una relación que establece que el consumo $\left(C_{t}\right)$, es una función de ingreso permanente $\left(Y_{t}^{p}\right)$.

Para la estimación de esta última variable se usa como "proxy" el ingreso esperado $\left(Y_{t}^{*}\right)$ que se supone igual al ingreso esperado del período anterior $\left(\mathrm{Y}_{\mathrm{t}-1}^{*}\right)$ más una fracción $(f)$ del error cometido en la predicción del ingreso esperado en $t-1\left(\mathrm{Y}_{\mathrm{t}-1}^{*}\right)$, con respecto al ingreso corriente observado $\left(Y_{t-1}\right)$, es decir:

$$
\left(Y_{t-1}-\mathrm{Y}_{\mathrm{t}-1}\right)
$$

en resumen:

1) $C_{t}=\mathrm{k} \mathrm{Y}_{\mathrm{t}}^{\mathrm{p}}$

2) $Y_{t}^{p}=Y_{t}^{*}$

3) $Y_{t}^{*}=\mathrm{Y}_{\mathrm{t}}^{*}+\mathrm{f}\left(\mathrm{Y}_{\mathrm{t}-1}-\mathrm{Y}_{\mathrm{t}-1}^{*}\right) \quad$ o bien,

4) $Y_{t}^{*}=(1-\mathrm{f}) \mathrm{Y}_{\mathrm{t}-1}^{*}+\mathrm{f} \mathrm{Y}_{\mathrm{t}-1}$

Si desarrollamos el ingreso esperado en $\mathrm{t}-1$, o sea $\mathrm{Y}^{*}-1$ obtenemos:

5. $Y_{t}^{*}=(1-\mathrm{f})(1-\mathrm{f}) \mathrm{Y}_{\mathrm{t}-2}^{*}+\mathrm{f} \mathrm{Y}_{\mathrm{t}-2}+\mathrm{f} \mathrm{Y}_{\mathrm{t}-1}$ 
Que a su vez es igual a:

6) $Y_{t}^{*}=(1-\mathrm{f})^{2} \mathrm{Y}_{\mathrm{t}-2}^{*}+(1-\mathrm{f}) \mathrm{fY}_{\mathrm{t}-2}+\mathrm{fY}_{\mathrm{t}-1}$

Y si desarrollamos $Y_{T-2}^{*}$

7) $Y_{t}^{*}=[1-\mathrm{f}]^{3} \mathrm{Y}_{\mathrm{t}-3}^{*}+(1-\mathrm{f})^{2} \mathrm{fY}_{\mathrm{t}-3}+(1-\mathrm{f}) \mathrm{fY}_{\mathrm{t}-2}+\mathrm{fY}_{\mathrm{t}-1}$

Recordemos términos obtenemos:

8) $Y_{t}^{*}=(1-\mathrm{f})^{3} \mathrm{Y}_{\mathrm{t}-3}^{*}+\mathrm{f}\left[(1-\mathrm{f})^{2} \mathrm{Y}_{\mathrm{t}-3}+(1-\mathrm{f}) \mathrm{Y}_{\mathrm{t}-2}+\mathrm{Y}_{\mathrm{t}-1}\right\rfloor$

Desarrollado toda la serie de ingresos esperados para $t-4, \mathrm{t}-3 \ldots \mathrm{t}-\mathrm{n}$, obtenemos :

9) $\quad Y_{t}=(1-\mathrm{f})^{n} \mathrm{Y}_{\mathrm{t}-\mathrm{n}}^{*}+\mathrm{f}\left\lfloor(1-\mathrm{f})^{n-1} \mathrm{Y}_{\mathrm{t}-(\mathrm{n}-1)}+(1-\mathrm{f})^{n-2} \mathrm{Y}_{\mathrm{t}-(\mathrm{n}-2)} \ldots+\ldots+(1-\mathrm{f}) \mathrm{Y}_{\mathrm{t}-2}+\mathrm{Y}_{\mathrm{t}-1}\right\rfloor$

o, en forma reducida,

10) $Y_{t}^{*}=(1-\mathrm{f})^{n} \mathrm{Y}_{\mathrm{t}-\mathrm{n}}^{*}+\mathrm{f} \sum_{\mathrm{j}=1}^{\mathrm{n}}(1-\mathrm{f})^{n-j} \mathrm{Y}_{\mathrm{t}-(\mathrm{n}-\mathrm{j}+1)}$

11) $Y_{t}^{*}=\sum_{\mathrm{j}=1}^{\mathrm{n}}(1-\mathrm{f})^{n-\mathrm{j}} \mathrm{Y}_{\mathrm{t}-(\mathrm{n}-\mathrm{j}+1)}$

Enseguida derivamos $Y_{t \mathrm{t} 1}^{*}$

12) $Y_{t-1}^{*}=(1-\mathrm{f}) \mathrm{Y}_{\mathrm{T}-2}^{*}+\mathrm{fY}_{\mathrm{t}-2} \mathrm{o}$, en forma reducida:

13) $Y_{t-1}^{*}=\mathrm{f} \sum_{\mathrm{j}=1}^{\mathrm{n}}(1-\mathrm{f})^{n-j} \mathrm{Y}_{\mathrm{t}-(\mathrm{n}-\mathrm{j}+2)}$

Por lo tanto, el consumo del año t será igual a 
14) $C_{t-1}=\mathrm{kf} \sum_{\mathrm{j}=1}^{\mathrm{n}}(1-\mathrm{f})^{n-j} \mathrm{Y}_{\mathrm{t}-(\mathrm{n}-\mathrm{j}+1)}$

Y el consumo de un año t-1 será igual a:

15) $C_{t-1}=\mathrm{kf} \sum_{\mathrm{j}=1}^{\mathrm{n}}(1-\mathrm{f})^{n-\mathrm{j}} \mathrm{Y}_{\mathrm{t}-(\mathrm{n}-\mathrm{j}+2)}$

Si ahora restamos $(1-f) C_{t-1}$ de $C_{t}$, obtenemos:

16) $C_{t}-(1-\mathrm{f}) \mathrm{C}_{\mathrm{t}-1}=\mathrm{k} \mathrm{fY}_{\mathrm{t}-1}$

Por ejemplo: para $n=4$

17) $C_{t}=\mathrm{kf}(1-\mathrm{f})^{3} \mathrm{Y}_{\mathrm{t}-4}+\mathrm{kf}(1-\mathrm{f})^{2} \mathrm{Y}_{\mathrm{t}-3}+\mathrm{kf}(1-\mathrm{f}) \mathrm{Y}_{\mathrm{t}-2}+\mathrm{kf} \mathrm{Y}_{\mathrm{t}-1}$

18) (1- f) $\mathrm{C}_{\mathrm{t}-1}=\mathrm{kf}(1-\mathrm{f})^{3} \mathrm{Y}_{\mathrm{t}-4}+\mathrm{kf}(1-\mathrm{f})^{2} \mathrm{Y}_{\mathrm{t}-3}+\mathrm{kf}(1-\mathrm{f}) \mathrm{Y}_{\mathrm{t}-2}$

Restando 18 de 17 se obtiene 16

Por lo tanto, podemos estimar el $C_{t}$ con la siguiente

función:

19) $C_{t}=\mathrm{kf}_{\mathrm{t}-1}+(1-\mathrm{f}) \mathrm{C}_{\mathrm{t}-1} \quad \mathrm{o}$, en otros términos:

20) $C_{t}=\mathrm{A}_{0} \mathrm{Y}_{\mathrm{t}-1}+\mathrm{A}_{1} \mathrm{C}_{\mathrm{t}-1}$, en donde $A_{o}=\mathrm{kf}, \mathrm{A}_{1}=(1-\mathrm{f})$

Se tomó una serie de datos anuales de 1961 a 1976 para el Producto Interno Neto $\left(\mathrm{Y}_{\mathrm{t}}\right)$ y de Consumo $\left(\mathrm{C}_{\mathrm{t}}\right)$, ambos a precios de 1960. Los resultados obtenidos en la regresión fueron los siguientes: 
21) $C_{t}=4.0784+0.5674 \mathrm{Y}_{\mathrm{t}-1}+0.3987 \mathrm{C}_{\mathrm{t}-1}$

(3.72) (2.25)

$R=.9981$

.5674 es el valor de la propensión marginal a consumir del ingreso corriente, y la propensión marginal a consumir el ingreso permanente $(k)$ la obtenemos como sigue:

Puesto que: $A_{o}=\mathrm{kf}, \mathrm{A}_{1}=(1-\mathrm{f})$; entonces:

$$
k=\frac{\mathrm{A}_{\mathrm{o}}}{1-\mathrm{A}_{1}}=\frac{.5674}{.7013}
$$

La ecuación original del consumo como función del ingreso permanente será entonces:

22) $C_{t}=.81 \mathrm{Y}_{\mathrm{t}}^{\mathrm{p}}$ 


\section{APENDICE 5}

\section{Cálculos del Excedente Petrolero}

A fin de destacar las divergencias entre la medición contable del excedente generado por PEMEX y una adecuada medición económica, presentamos en páginas subsecuentes correcciones en algunos rubros de ingresos y de gastos que resultan de evaluar el producto y los servicios de factores en términos del valor que tienen para la economía en su conjunto.

Las correcciones propuestas no son de ninguna manera exhaustivas, en el sentido de presentar "todas" las correcciones que es pertinente hacer para transformar un concepto contable de ahorro corriente en un concepto económico, tienen tan solo el carácter ilustrativo de destacar la existencia de tales discrepancias.

1. Excedentes financieros $(E F)$ (Cuadro 1)

$E F=\mathrm{a}+\mathrm{B}+\mathrm{c}-\mathrm{d}$

a) Ingresos por exportaciones, convertidos a pesos con una tasa de cambio fija que PEMEX supone de 22.8 pesos por dólar.

b) Ingresos por ventas domésticas, valuadas a los precios subsidiados que paga el consumidor nacional.

c) Otros ingresos.

d) Costos de operación y otros gastos valuados a precios de mercado. Excluye el pago de impuestos federales.

\section{Excedentes económicos brutos (EEB) (Cuadro 5)}


$E E B=\mathrm{a}+\mathrm{b}-\mathrm{c}-\mathrm{d}-\mathrm{e}$

a) Exportaciones petroleras valoradas a precios internacionales y transformadas a pesos con una tasa de cambio ajustada por las variaciones en la paridad del poder de compra (ver cuadro No. 2)

b) Ventas domésticas valoradas a precios internacionales; para lo cual, con la composición del consumo de diferentes productos petroleros en 1977, se obtuvo un precio promedio ponderado. (Véase cuadro No.3).

c) Costo total de oportunidad de la mano de obra empleada por PEMEX. Se calculó como las remuneraciones promedio por trabajador en los sectores minero (exceptuando extracción de petróleo), y manufacturero. (Véase cuadro No. 4).

d) Gastos por intereses según la proyección de PEMEX.

e) Otros egresos con excepción de sueldos y salarios. Se supone que su precio social es igual al privado.

3. Excedentes económicos netos (EEN) (Cuadro 6, 7 y 8)

$E E N=\mathrm{a}-\mathrm{b}$

a) Excedente Económico Bruto (del cuadro 5).

b) Costo de oportunidad del capital.

Tenemos tres versiones de cálculo para el EEN según la hipótesis adoptada con respecto a la estimación del "costo de uso" del capital.

$\underline{1^{\mathrm{a}} \text {. versión }}$ (cuadro 6) 
A los activos fijos en operación se les imputa un costo de oportunidad de $7.5 \%$ anual y para las inversiones programadas se usa un $17.5 \%$ que se estima como la tasa de ganancia de la economía.

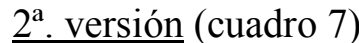

El costo de los activos fijos en operación se estima como $7.5 \%$ y $13.7 \%$ para las nuevas inversiones, ésta última tasa se estima como promedio de la tasa media de ganancia de la economía y la tasa del interés del endeudamiento externo.

\section{$\underline{3^{\mathrm{a}} \text {. versión }}$ (cuadro 8)}

Se considera que los activos en operación no tienen costo de oportunidad y sólo a las inversiones programadas se les imputa una tasa del $13.7 \%$ 


\section{Cuadro Básico A}

Diversas Opciones en la Cuantificación de los Excedentes Petroleros

(Miles de millones de pesos corrientes y \% de ingresos corrientes)

\begin{tabular}{|c|c|c|c|c|c|c|c|c|c|c|c|c|c|}
\hline & 1977 & 1978 & 1979 & 1980 & 1981 & 1982 & $1977-1982$ & 1977 & 1978 & 1979 & 1980 & 1981 & 1982 \\
\hline Concepto & Absolutos & $\%$ & Absolutos & $\%$ & Absolutos & $\%$ & Absolutos & $\%$ & Absolutos & $\%$ & Absolutos & $\%$ & $\begin{array}{r}\text { Promedio } \\
\text { de los } \%\end{array}$ \\
\hline $\begin{array}{c}\text { Excedente Financiero } \\
\text { (Cuadro 1) }\end{array}$ & 37.6 & 27.1 & 57.6 & 32.3 & 99.9 & 40.8 & 148.4 & 44.2 & 177.5 & 44.1 & 200.8 & 43.8 & 38.7 \\
\hline $\begin{array}{c}\text { Excedente Económico } \\
\text { (Cuadro 5) }\end{array}$ & 92.4 & 66.7 & 124.0 & 69.4 & 188.2 & 76.9 & 267.0 & 79.6 & 320.2 & 79.6 & 377.8 & 79.9 & 75.4 \\
\hline $\begin{array}{l}\text { Excedente Económico } \\
\text { Neto Según Hipótesis I } \\
\text { (Cuadro 6) }\end{array}$ & 77.1 & 55.8 & 98.3 & 55.0 & 149.9 & 61.3 & 211.9 & 63.1 & 247.5 & 61.5 & 286.0 & 60.5 & 59.5 \\
\hline $\begin{array}{l}\text { Excedente Económico } \\
\text { Neto Según Hipótesis Ii } \\
\text { (Cuadro 7) }\end{array}$ & 78.4 & 56.6 & 101.9 & 57.1 & 156.1 & 63.9 & 220.0 & 65.5 & 261.5 & 65.0 & 304.3 & 64.4 & 62.1 \\
\hline $\begin{array}{l}\text { Excedente Económico } \\
\text { Neto Según Hipótesis Iii } \\
\text { (Cuadro } 8)\end{array}$ & 87.5 & 63.1 & 110.6 & 62.0 & 164.4 & 67.2 & 229.8 & 68.4 & 268.9 & 66.8 & 311.4 & 65.9 & 65.6 \\
\hline Ingresos Corrientes & 138.6 & 100.0 & 178.6 & 100.0 & 244.7 & 100.0 & 335.7 & 100.0 & 402.4 & 100.0 & 472.8 & 100.0 & \\
\hline
\end{tabular}

\section{Cuadro 1}

Excedentes Financieros $\stackrel{1 /}{ }$

(Miles de millones de pesos corrientes)

\begin{tabular}{lrrrrrr}
\hline \multicolumn{1}{c}{ Concepto } & 1977 & 1978 & \multicolumn{1}{c}{1979} & \multicolumn{1}{c}{1980} & \multicolumn{1}{c}{1981} & \multicolumn{1}{c}{1982} \\
\hline 1.- Recursos propios ${ }^{2}-$ & 88.5 & 118.1 & 163.5 & 225.5 & 269.9 & 313.9 \\
2.- Egresos con excepción de Imp. Fed. & 50.9 & 60.5 & 63.6 & 77.1 & 92.4 & 107.1 \\
3.- Excedente $=1-2$ & 37.6 & 57.6 & 99.9 & 148.4 & 177.5 & 206.8 \\
4.- Endeudamiento neto & 16.9 & 33.9 & 35.6 & 37.8 & 35.5 & 38.0 \\
5.- Recursos totales $=3+4$ & 54.5 & 91.5 & 135.5 & 186.2 & 213.0 & 244.8 \\
6.- Disposición $=7+8$ & 54.5 & 91.5 & 135.5 & 186.2 & 213.0 & 244.8 \\
7.- Impuestos federales & 18.9 & 28.0 & 54.8 & 80.2 & 96.8 & 116.6 \\
8.- Inversión programada & 35.6 & 63.5 & 80.7 & 106.0 & 116.2 & 128.2 \\
\hline
\end{tabular}

2 Ventas interiores, ventas exteriores y otros ingresos, ventas exteriores y otros ingresos. 
Cuadro 2

Exportaciones de Pemex

\begin{tabular}{|c|c|c|c|c|c|c|}
\hline Concepto & 1977 & 1978 & 1979 & 1980 & 1981 & 1982 \\
\hline Exportación en miles de barriles/día ${ }^{\underline{I}}$ & 209.0 & 408.0 & 783.0 & $1,122.0$ & $1,301.0$ & $1,483.0$ \\
\hline llones de barriles/año & 76.2 & 148.9 & 285.8 & 409.5 & 474.9 & 541.3 \\
\hline or barril (dólares) $\stackrel{2 l}{-}$ & 13.4 & 13.4 & 14.3 & 14.9 & 15.5 & 16.0 \\
\hline $\begin{array}{l}\text { Exportaciones corregidas por precio } \\
\text { (millones de dólares) }\end{array}$ & $1,021.1$ & $1,995.0$ & $4,086.9$ & $6,101.6$ & $7,361.0$ & $8,660.8$ \\
\hline Tipo de cambio $\underline{3}$ & 22.6 & 22.7 & 24.4 & 26.0 & 27.0 & 28.0 \\
\hline $\begin{array}{l}\text { Exportaciones corregidas por precio y tipo de cambio. } \\
\text { (Miles de millones de pesos corrientes) }\end{array}$ & 23.1 & 45.3 & 99.7 & 158.6 & 198.7 & 242.5 \\
\hline
\end{tabular}

Cuadro 3

Determinación de Precios Relativos Promedio de los Productos de Pemex

1977

\begin{tabular}{|c|c|c|c|c|c|c|}
\hline & $\begin{array}{c}\text { Miles de } \\
\text { millones } \\
\text { de pesos } \\
\text { corrientes } \\
\text { (1) }\end{array}$ & $\begin{array}{l}\text { Estructura } \\
\text { Porcentual } \\
\qquad \text { (2) }\end{array}$ & $\begin{array}{c}\text { Precio } \\
\text { Internacional } \\
\text { (pesos) } \\
\text { (3) }\end{array}$ & $\begin{array}{l}\text { Precio } \\
\text { Doméstico } \\
\text { (pesos) } \\
\text { (4) }\end{array}$ & $\begin{array}{l}\text { Precios } \\
\text { Relativos } \\
(5)=(3) \div(4)\end{array}$ & $\begin{array}{c}\text { Precios } \\
\text { Relativos } \\
\text { Ponderados } \\
(5)=(2)(5)\end{array}$ \\
\hline $\begin{array}{l}\text { Ventas Domésticas de los } \\
\text { Principales Productos de PEMEX }\end{array}$ & 39,329 & 100.0 & & & & 2.0937 \\
\hline Gas olinas & 22,595 & 59.0 & 40.0 & 46.0 & 0.8696 & 0.5131 \\
\hline Kerosinas & 3,030 & 7.9 & 40.0 & 13.7 & 2.9197 & 0.2307 \\
\hline D i e s e 1 & 5,991 & 15.6 & 40.0 & 9.9 & 4.0404 & 0.6303 \\
\hline Combustoleo & 3,149 & 8.2 & 12.0 & 1.8 & 6.6667 & 0.5467 \\
\hline Gas $1 \mathrm{icuado}$ & 3,564 & 9.3 & 135.0 & 72.6 & 1.8595 & 0.1729 \\
\hline
\end{tabular}

1/ basándose en la Alternativa 1 de PEMEX de Feb. 9 de 1979.

2/ Se supone que el precio del crudo se incrementa en $2 / 3$ de la inflación mundial en los últimos tres años del periodo.

3/ El tipo de cambio es el que corresponde a las variaciones en el índice de la paridad de poder de compra. 
Cuadro 4

Costos de Oportunidad del Trabajo Empleado por Pemex

\begin{tabular}{cccc}
\hline Años & $\begin{array}{c}\text { Costo de } \\
\text { Oportunidad } \\
\text { (Salarios } \\
\text { Promedio } \\
\text { en miles de pesos) } \\
(1)\end{array}$ & $\begin{array}{c}\text { Personal } \\
\text { Ocupado }{ }^{1 /} \\
\text { (miles) }\end{array}$ & $\begin{array}{c}\text { Fondo de } \\
\text { Salarios } \\
\text { (millones de pesos } \\
\text { corrientes) }\end{array}$ \\
\hline 1977 & 72.123 & 96.7 & $(3)$ \\
1978 & 84.600 & 105.0 & $6,974.3$ \\
1979 & 97.438 & 110.0 & $8,883.1$ \\
1980 & 111.214 & 116.0 & $10,718.2$ \\
1981 & 126.432 & 122.0 & $12,900.8$ \\
1982 & 143.381 & 128.0 & $18,424.7$ \\
\hline
\end{tabular}

2 El Costo de oportunidad por trabajar es igual a las remuneraciones promedio por trabajador en los sectores minero (exceptuando extracción del petróleo y manufacturero. Además se supone que los salarios promedio se incrementan para mantener los salarios reales constantes.

1/ El personal ocupado en PEMEX se tomó del trabajo de la SPP titulado "Bases del Plan Global de Desarrollo 1978 $1982 "$ 


\section{Cuadro 5}

Excedentes Económicos Brutos

(Miles de millones de pesos corrientes)

\begin{tabular}{|c|c|c|c|c|c|c|}
\hline Concepto & 1977 & 1978 & 1979 & 1980 & 1981 & 1982 \\
\hline RECURSOS PROPIOS & 138.6 & 178.6 & 244.7 & 335.7 & 402.4 & 472.8 \\
\hline Ventas internas $\stackrel{1 /}{ }$ & $\overline{103.7}$ & $\overline{126.7}$ & $\overline{142.6}$ & $\overline{165.8}$ & $\overline{184.5}$ & $\overline{200.4}$ \\
\hline Ventas exteriores $\underline{2 l}$ & 23.1 & 45.3 & 99.7 & 158.6 & 198.7 & 242.7 \\
\hline Importación de productos petrolíferos y petroquímicos $\underline{3}$ & 8.0 & 6.3 & 3.8 & -4.5 & -11.5 & -20.9 \\
\hline Ventas netas & 15.1 & 39.0 & 95.9 & 163.1 & 210.2 & 263.6 \\
\hline Otros ingresos & 19.8 & 12.9 & 6.2 & 6.8 & 7.7 & 8.8 \\
\hline EGRESOS & $\underline{35.0}$ & $\underline{37.8}$ & $\underline{35.1}$ & $\underline{41.6}$ & 49.0 & $\underline{55.3}$ \\
\hline Egresos de operación excepto sueldos y salarios & 21.7 & 27.5 & 30.6 & 36.2 & 42.8 & 47.9 \\
\hline Otros gastos & 13.3 & 10.3 & 4.5 & 5.4 & 6.2 & 7.4 \\
\hline VALOR AGREGADO BRUTO & 103.6 & 140.8 & 209.6 & 294.1 & 353.4 & 417.5 \\
\hline Sueldos y salarios $\stackrel{4}{ }$ & 6.9 & $\overline{3.9}$ & 10.7 & $\overline{12.9}$ & $\overline{15.4}$ & $\overline{18.3}$ \\
\hline Intereses & 4.3 & 7.9 & 10.7 & 14.2 & 17.8 & 21.4 \\
\hline Superávit de operación & 92.4 & 121.0 & 188.2 & 267.0 & 320.2 & 377.8 \\
\hline EXCEDENTE ECONÖMICO BRUTO & 92.4 & 124.0 & 188.2 & 267.0 & 320.2 & 377.8 \\
\hline
\end{tabular}

1/ Ventas internas valorizadas a precios internacionales (el precio promedio de venta internacional es 2.0937 veces mayor que 1 precio doméstico promedio como puede verse en el cuadro No. 3).

2/ Ventas externas ajustadas por mayor tipo de cambio y por mayores precios internacionales del barril de crudo, véase cuadro No. 2.

3/ Ajustados por nuevo tipo de cambio, véase cuadro No. 2.

4/ Calculados al costo de oportunidad del trabajo que es al salario promedio en los sectores minero y manufacturero. Véase cuadro No. 4. 
Cuadro 6

Excedente Económico Neto y su Disposición

(Hipótesis I) *

(Miles de millones de pesos corrientes)

\begin{tabular}{|c|c|c|c|c|c|c|}
\hline Concepto & 1977 & 1978 & 1979 & 1980 & 1981 & 1982 \\
\hline EXCEDENTE ECONOMICO $\stackrel{1 /}{ }$ & 92.4 & 124.0 & 188.2 & 267.0 & 320.2 & 377.8 \\
\hline COSTO DE CAPITAL & 15.3 & 25.7 & 38.3 & 55.1 & 72.7 & 91.6 \\
\hline 1.1 Activos fijos netos acumulados (hasta 31 de dic. $1976 \stackrel{2 /}{2}$ & 121.9 & 115.8 & 110.0 & 104.5 & 99.3 & 94.3 \\
\hline 1.2 Costo del activo fijo neto (hasta 31 de dic. $1976^{3 /}$ & 9.1 & 8.7 & 8.3 & 7.8 & 7.4 & 7.1 \\
\hline 1.3 Incremento en activo fijo neto ${ }^{4 /}$ & 35.6 & 97.3 & 173.1 & 270.4 & 373.1 & 482.7 \\
\hline 1.4 Costo del activo fijo neto acum. (en 1977-1982) ${ }^{\underline{5}}$ & 6.2 & 17.0 & 30.3 & 47.3 & 65.3 & 84.5 \\
\hline EXCEDENTE ECONÓMICO NETO & 77.1 & 98.3 & 149.9 & 211.9 & 247.5 & 286.0 \\
\hline DISPOSICIONES & 108.6 & 157.7 & 210.0 & 272.8 & 309.4 & 349.5 \\
\hline 4.1 Impuestos federales $6 /$ & 18.9 & 28.0 & 54.8 & 80.2 & 96.8 & 116.6 \\
\hline 4.2 Subsidio a consumidores $\stackrel{7}{ }$ & 54.1 & 66.2 & 74.5 & 86.6 & 96.4 & 104.7 \\
\hline 4.3 Inversión fija bruta de PEMEX $6 /$ & 35.6 & 63.5 & 80.7 & 106.0 & 116.2 & 128.2 \\
\hline $\begin{array}{l}\text { 5. DISPOSICIÓN-EXCEDENTE ECONÓMICO (NETO } \\
\text { FALTANTE POR FINANCIAR) }\end{array}$ & 31.5 & 59.4 & 60.1 & 66.3 & 61.9 & 63. \\
\hline
\end{tabular}

Notas: $\frac{1}{2}$ Tomado del cuadro No. 5.

2/ Al activo fijo bruto de 128. 318.318 miles de millones de pesos en Dic. de 1976 se le aplicó una tasa de depreciación del 5\% anual para proyectarlo a $1977-1982$.

3/ El costo de oportunidad del capital acumulado hasta el 31 de Dic. de 1976 lo consideramos como de $7.5 \%$ anual.

4/ Al incremento del activo fijo bruto en 1977 - 1982 se le aplicó una tasa de depreciación del 5\% anual.

5/ El costo de oportunidad del incremento del activo fijo neto en 1877 - 1982 se consideró que es del $17.5 \%$ anual (tasa de ganancia promedio doméstico).

6 Son los datos que presenta PEMEX en su alternativa t de Feb. 9 de 1979.

7 El subsidio es el diferencial entre ventas internas valorizadas a precios internacionales menos ventas internas valorizadas a precios domésticos. 
Cuadro 7

Excedente Económico Neto y su Disposición

(Hipótesis II) $^{*}$

(Miles de millones de pesos corrientes)

\begin{tabular}{|c|c|c|c|c|c|c|c|}
\hline Concepto & & 1977 & 1978 & 1979 & 1980 & 1981 & 1982 \\
\hline 1. EXCEDENTE ECONOMICO BRUTO ${ }^{1 /}$ & & 92.4 & 124.0 & 188.2 & 267.0 & 320.2 & 377.8 \\
\hline 2. COSTO DE CAPITAL & & 14.0 & 22.1 & 32.1 & 45.0 & 58.7 & 73.5 \\
\hline 2.1 Activos fijos netos acum. (hasta 31 de dic. $1976 \stackrel{2 /}{2}$ & & 121.9 & 115.8 & 110.0 & 104.5 & 99.3 & 94.3 \\
\hline 2.2Costo del activo fijo neto acum. (hasta 31 de dic. 1976 3l & & 9.1 & 8.7 & 8.3 & 7.8 & 7.4 & 7.1 \\
\hline 2.3 Incremento en activo fijo neto $\frac{4}{-}$ & & 35.6 & 97.3 & 173.1 & 270.4 & 373.1 & 482.7 \\
\hline 2.4 Costo del activo fijo neto acum. (en 1977-1982) $\underline{5}$ & & 4.9 & 13.4 & 23.8 & 37.2 & 51.3 & 66.4 \\
\hline 3. EXCEDENTE ECONÓMICO NETO & & 78.4 & 101.9 & 156.1 & 222.0 & 261.5 & 304.3 \\
\hline 4. DISPOSICIONES & & 108.6 & 157.7 & 210.0 & 272.8 & 309.4 & 349.5 \\
\hline 4.1 Impuestos federales $\underline{6}$ & & 18.9 & 28.0 & 54.8 & 80.2 & 96.8 & 116.6 \\
\hline 4.2 Subsidio a consumidores ${ }^{7 /}$ & & 54.1 & 66.2 & 74.5 & 86.6 & 96.4 & 104.7 \\
\hline 4.3 Inversión fija bruta de PEMEX ${ }^{6}$ & & 35.6 & 63.5 & 80.7 & 106.0 & 116.2 & 128.2 \\
\hline $\begin{array}{l}\text { 5. DISPOSICIONES-EXCEDENTE } \\
\text { (FALTANTE POR FINANCIAR) }\end{array}$ & NETO & 30.2 & 55.8 & 53.9 & 50.8 & 47.9 & 45.2 \\
\hline
\end{tabular}

Nota: $\frac{1}{2} \quad$ Tomado del cuadro No. 5 .

2/ Al activo fijo bruto de 128.318 miles de millones de pesos en Dic. de 1976 se le aplicó una tasa de depreciación del 5\% anual para proyectarlo a $1977-1982$.

3/ El costo de oportunidad del capital acumulado hasta el 31 de Dic. de 1976 lo consideramos como de $7.5 \%$ anual.

4/ Al incremento del activo fijo bruto en 1977 - 1982 se le aplicó una tasa de depreciación del 5\% anual.

5/ El costo de oportunidad del incremento del activo fijo neto en 1977 - 1982, se consideró que es del 13.75\% anual (suponiendo que el $50 \%$ de la I. F. B. es financiada por recursos externos con costo del 10\% anual).

6/ Son los datos que presenta PEMEX en su alternativa 1 Feb. 9 de 1979.

7/ El subsidio es el diferencial entre ventas internas valoradas a precios internacionales menos ventas internas valoradas a precios domésticos. 


\section{Cuadro 8}

\section{Excedente Económico Neto y su Disposición}

$$
\text { (Hipótesis Iii) * }
$$

(Miles de millones de pesos corrientes)

\begin{tabular}{|c|c|c|c|c|c|c|}
\hline Concepto & 1977 & 1978 & 1979 & 1980 & 1981 & 1982 \\
\hline 1. EXCEDENTE ECONOMICO BRUTO $\stackrel{\text { II }}{ }$ & 92.4 & 124.0 & 188.2 & 267.0 & 320.2 & 377.8 \\
\hline 2. COSTO DE CAPITAL & 4.9 & 13.4 & 23.8 & 37.2 & 51.3 & 66.4 \\
\hline Incremento en el Activo fijo neto $\underline{2 l}$ & 35.6 & 97.3 & 173.1 & 270.4 & 373.0 & 482.7 \\
\hline Costo de los A.F.N. acum. en 1977-1982 르 & 4.9 & 13.4 & 23.8 & 37.2 & 51.3 & 66.4 \\
\hline 3. EXCEDENTE ECONÓMICO NETO & 87.5 & 110.6 & 164.4 & 229.8 & 268.9 & 311.4 \\
\hline 4. DISPOSICIONES & 108.6 & 157.7 & 210.0 & 272.8 & 309.4 & 349.5 \\
\hline 4.1 Impuestos federales 4 & 18.9 & 28.0 & 54.8 & 80.2 & 96.8 & 116.6 \\
\hline 4.2 Subsidio a consumidores $\frac{5 /}{2}$ & 54.1 & 66.2 & 74.5 & 86.6 & 96.4 & 104.7 \\
\hline 4.3 Programa de I.F.B. de PEMEX ${ }^{4 /}$ & 35.6 & 63.5 & 80.7 & 106.0 & 116.2 & 128.2 \\
\hline $\begin{array}{l}\text { 5. DISPOSICIONES-EXCEDENTE ECONOMICO NETO (FALTANTE } \\
\text { POR FINANCIAR) }\end{array}$ & 21.1 & 47.1 & 45.6 & 43.0 & 40.5 & 38.1 \\
\hline
\end{tabular}

1/ Tomando del cuadro No.5

2/ La inversión Fija Bruta acumulada hasta el 31 de Di. 1976, se le aplicó costo de oportunidad de cero. A la I. F. B. acumulada en 1977 - 1982 se le aplicó una tasa de depreciación del 5\% anual.

3/ Se aplicó un costo de oportunidad a la I. F. N. Del 13.75\% que es la media del costo de oportunidad doméstico (20\% y el costo de recursos del exterior (10\%).

4/ Son los datos que presenta PEMEX en su alternativa I de Feb. 9 de 1979.

5/ El subsidio es el diferencial entre ventas internas valoradas a precios internacionales menos ventas internas valoradas a precios domésticos. 


\section{Cuadro Básico B}

Diversas Opciones en la Cuantificación de los Excedentes Petroleros $1 /$

(Miles de millones de pesos de 1977 y por ciento respecto a ingresos corrientes)

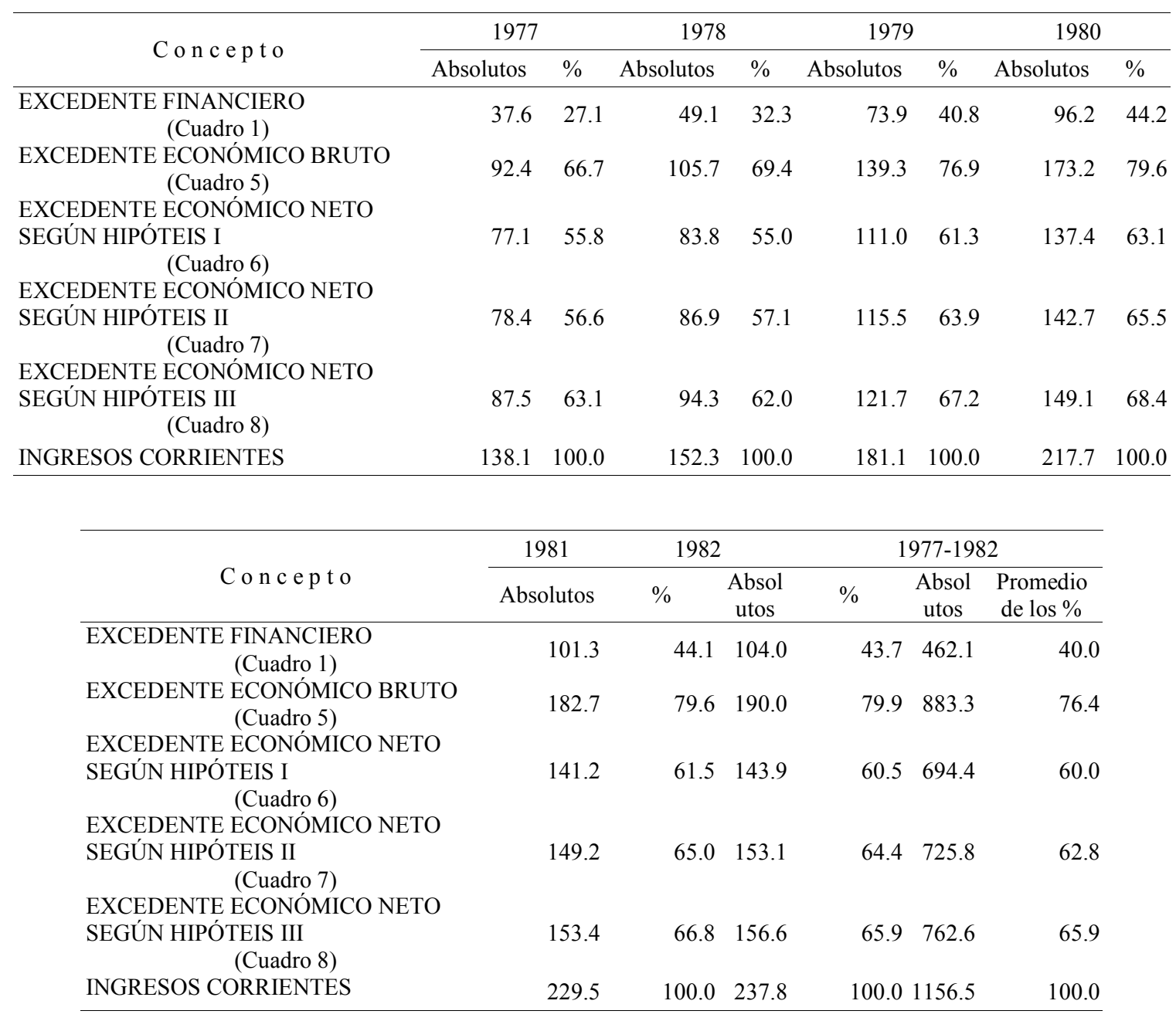




\section{Cuadro I B}

Excedentes Financieros ${ }^{1 /}$

(Miles de millones de pesos de 1977)

\begin{tabular}{|c|c|c|c|c|c|c|}
\hline Concepto & 1977 & 1978 & 1979 & 1980 & 1981 & 1982 \\
\hline 1. Recursos Propios $2 / 1$ & 88.5 & 100.7 & 121.0 & 146.2 & 154.0 & 157.9 \\
\hline 2. Egresos con excepción de Imp. Federales & 50.9 & 51.6 & 47.1 & 50.0 & 52.7 & 53.9 \\
\hline 3. Excedente $=1-2$ & 37.6 & 49.1 & 73.9 & 96.2 & 101.3 & 104.2 \\
\hline 4. Endeudamiento neto & 16.9 & 28.9 & 26.4 & 24.5 & 320.5 & 19.1 \\
\hline 5. Recursos totales $=3+4$ & 54.5 & 78.1 & 100.3 & 120.8 & 121.5 & 123.1 \\
\hline 6. Disposición $=7+8$ & 54.5 & 78.1 & 100.3 & 120.8 & 121.5 & 123.1 \\
\hline 7. Imp. Federales & 18.9 & 23.9 & 40.6 & 52.0 & 55.2 & 58.7 \\
\hline 8. Inversión programada & 35.6 & 54.1 & 59.7 & 68.7 & 66.3 & 64.5 \\
\hline
\end{tabular}

Cuadro 5 B

Excedentes Económicos Brutos *

(Miles de millones de pesos de 1979)

\begin{tabular}{lrrrrrr}
\hline \multicolumn{1}{c}{ Concepto } & \multicolumn{1}{c}{1977} & \multicolumn{1}{c}{1978} & \multicolumn{1}{c}{1979} & \multicolumn{1}{c}{1980} & \multicolumn{1}{c}{1981} & \multicolumn{1}{c}{1982} \\
\hline RECURSOS PROPIOS & 138.6 & 152.3 & 181.3 & 217.7 & 229.5 & 237.8 \\
Ventas Internas & 103.7 & 108.0 & 105.6 & 107.5 & 105.2 & 100.8 \\
Ventas Exteriores & 23.1 & 38.6 & 73.8 & 102.9 & 113.3 & 122.1 \\
Importación de Productos & & & & & & \\
Petrolíferos y Petroquímicos & 8.0 & 5.4 & 2.8 & -2.9 & -6.6 & -10.5 \\
Ventas Netas & 15.1 & 33.2 & 71.0 & 105.8 & 119.9 & 132.6 \\
Otros Ingresos & 19.8 & 11.0 & 71.0 & 4.4 & 4.4 & 4.4 \\
EGRESOS & 35.0 & 32.2 & 4.6 & 27.0 & 28.0 & 27.8 \\
Egresos de Operación Excepto & & & & & & \\
Sueldos y Salarios & 21.7 & 23.4 & 26.0 & 23.5 & 24.4 & 24.1 \\
Otros Gastos & 13.3 & 8.9 & 3.3 & 3.5 & 3.5 & 3.7 \\
VALOR AGREGADO BRUTO & 103.6 & 120.0 & 155.1 & 190.7 & 201.6 & 210.0 \\
Sueldos y Salarios & 6.9 & 7.6 & 7.9 & 8.4 & 8.8 & 9.2 \\
Intereses & 4.3 & 6.7 & 7.9 & 9.2 & 10.2 & 10.8 \\
Superávit de Operación & 92.4 & 105.7 & 139.3 & 173.2 & 182.7 & 190.0 \\
EXCEDENTE ECONOMICO BRUTO & 92.4 & 105.7 & 139.3 & 173.2 & 182.7 & 190.0 \\
\hline
\end{tabular}

2 Ventas interiores, ventas exteriores y otros ingresos. 
Cuadro 6 B

Excedente Económico Neto y su Disposición

Hipótesis I

(Miles de millones de pesos de 1977) ${ }^{*}$

\begin{tabular}{|c|c|c|c|c|c|c|}
\hline Concepto & 1977 & 1978 & 1979 & 1980 & 1981 & 1982 \\
\hline 1. EXCEDENTE ECONÓMICO BRUTO & 92.4 & 105.7 & 139.3 & 173.2 & 182.7 & 190.0 \\
\hline 2. COSTO DE CAPITAL & 15.3 & 21.9 & 28.3 & 35.7 & 41.5 & 46.0 \\
\hline 2.1 Activos Fijos Netos Acumulados (hasta el 31 de Dic. 1976) & 121.9 & 98.7 & 81.4 & 67.8 & 56.6 & 47.4 \\
\hline 2.2 Costo Activo Fijo Neto Acum. (hasta el 31 de Dic. 1976) & 9.1 & 7.4 & 6.1 & 5.1 & 4.2 & 3.6 \\
\hline 2.3 Incremento en Activo Fijo Neto (en 1977-1982) & 35.6 & 82.9 & 128.1 & 175.4 & 212.8 & 242.8 \\
\hline 2.4 Costo del Incremento en Activo Fijo Neto (en 1977-1982) & 6.2 & 14.5 & 22.4 & 30.7 & 37.3 & 42.5 \\
\hline 3. EXCEDENTE ECONÓMICO NETO & 77.1 & 83.8 & 111.0 & 137.4 & 141.2 & 143.9 \\
\hline 4. DISPOSICIONES & 108.6 & 134.4 & 155.4 & 176.9 & 176.5 & 175.8 \\
\hline 4.1 Impuestos Federales & 18.9 & 23.9 & 40.6 & 52.0 & 55.2 & 58.7 \\
\hline 4.2 Subsidio a Consumidores & 54.1 & 56.4 & 55.1 & 56.2 & 55.0 & 58.7 \\
\hline 4.3 Inversión Fijo Bruta de PEMEX & 35.6 & 54.1 & 59.7 & 68.7 & 66.3 & 64.5 \\
\hline DISPOSICIÓN-EXCEDENTE ECONÓMICO NETO (faltante por Financiar) & 31.5 & 50.6 & 44.5 & 43.0 & 35.3 & 31.8 \\
\hline
\end{tabular}

\section{Cuadro 7 B}

Excedente Económico Neto y su Disposición *

Hipótesis II

(Miles de millones de pesos de 1977)

\begin{tabular}{|c|c|c|c|c|c|c|}
\hline Concepto & 1977 & 1978 & 1979 & 1980 & 1981 & 1982 \\
\hline 1. EXCEDENTE ECONÓMICO BRUTO & 92.4 & 105.7 & 139.3 & 173.1 & 182.7 & 190.0 \\
\hline 2. COSTO DE CAPITAL & 14.0 & 18.8 & 23.8 & 29.2 & 33.5 & 37.0 \\
\hline 2.1 Activos Fijos Acumulados (hasta el 31 de Dic. 1976) & 121.9 & 98.7 & 81.4 & 67.8 & 56.6 & 47.4 \\
\hline 2.2 Costo Activo Fijo Neto Acum.(hasta el 31 de Dic. 1976) & 9.1 & 7.4 & 6.1 & 5.1 & 4.2 & 3.6 \\
\hline 2.3 Incremento en Activo Fijo Neto & 35.6 & 82.9 & 128.1 & 175.4 & 212.8 & 242.8 \\
\hline 2.4 Costo de Activo Fijo Neto Acum. (en 1977-1982) & 4.9 & 11.4 & 17.6 & 24.1 & 29.3 & 33.4 \\
\hline 3. EXCEDENTE ECONOMICO NETO & 78.4 & 86.9 & 115.5 & 144.0 & 149.2 & 153.1 \\
\hline 4. DISPOSICIONES & 108.6 & 134.4 & 155.4 & 176.9 & 176.5 & 175.8 \\
\hline 4.1 Impuestos Federales & 18.9 & 23.9 & 40.6 & 52.0 & 55.2 & 58.7 \\
\hline 4.2 Subsidio a Consumidores & 54.1 & 56.4 & 55.1 & 56.2 & 55.0 & 52.7 \\
\hline 4.3 Inversión Fija Bruta de PEMEX & 35.6 & 54.1 & 59.7 & 68.7 & 66.3 & 64.5 \\
\hline DISPOSICIONES-EXCEDENTE ECONÓMICO (faltante por Financiar) & 30.2 & 47.6 & 39.9 & 32.9 & 27.3 & 22.7 \\
\hline
\end{tabular}

\footnotetext{
* Elaborado basándose en el cuadro No. 6 para deflactar usamos el índice de precios domésticos presentado por PEMEX en el trabajo de febrero 9 de 1979.
} 
Cuadro 8 B

Excedente Económico Neto y su Disposición *

Hipótesis III

(Miles de millones de pesos de 1977)

\begin{tabular}{lrrrrrr}
\hline \multicolumn{1}{c}{ Concepto } & 1977 & 1978 & 1979 & 1980 & \multicolumn{1}{c}{1981} & \multicolumn{1}{c}{1982} \\
\hline 1. EXCEDENTE ECONÓMICO BRUTO & 92.4 & 105.7 & 139.3 & 173.1 & 182.7 & 190.0 \\
2. COSTO DE CAPITAL & 4.9 & 11.4 & 17.6 & 24.1 & 29.3 & 33.4 \\
2.1 Incremento en el Activo Fijo Neto & 35.6 & 82.9 & 128.1 & 175.4 & 212.8 & 242.8 \\
2.2 Costo de los A.F.N. (Acum.) (en 1977 - 1982) & 4.9 & 11.4 & 17.6 & 24.1 & 29.3 & 33.4 \\
3. EXCEDENTE ECONÓMICO NETO & 87.5 & 94.3 & 121.7 & 149.0 & 153.4 & 156.6 \\
4. DISPOSICIONES & 108.6 & 134.4 & 155.4 & 176.9 & 176.5 & 175.8 \\
4.1 Impuestos Federales & 18.9 & 23.9 & 40.6 & 52.0 & 55.2 & 58.7 \\
4.2 Subsidio a Consumidores & 54.1 & 56.4 & 55.1 & 56.2 & 55.0 & 52.7 \\
4.3 Programa de I.F.B. de PEMEX & 35.6 & 54.1 & 59.7 & 68.7 & 66.3 & 64.5 \\
5. DISPOSICIONES-EXCEDENTE ECONÓMICO & 21.1 & 40.2 & 33.8 & 27.9 & 23.1 & 19.2 \\
(faltante por Financiar) & & & & & & \\
\hline
\end{tabular}




\section{APÉNDICE 6}

Discusión Sobre Varios Conceptos de Excedentes Petroleros.

Nos interesa cuantificar el total de excedentes económicos generados por PEMEX. Ello con el fin de incorporarlos adecuadamente a una Estrategia General de Desarrollo, en el cumplimiento de las siguientes metas:

a) Transformar la riqueza petrolera realizada en otras fuentes de ingreso permanente $y$,

b) Evitar fluctuaciones bruscas en las divisas y en el circulante que pongan en peligro la estabilidad de precios y de la tasa de cambio.

\section{Valoración de la producción e insumos a precios sociales}

Ante todo, reconocemos la conveniencia de establecer a través de un concepto operativo, una forma de medir los excedentes del petróleo.

Sin embargo, consideramos que contemplar el ahorro corriente de PEMEX antes de impuestos, comúnmente medidos, como medición del excedente petrolero, constituye una forma de evadir el problema de medición. Obviamente, si la medición del ahorro corriente de PEMEX se tomara directamente del reporte contable del organismo, el intento de establecer un concepto adecuado de excedente, se vería frustrado; quedando al arbitrio del "buen criterio contable", la medición relevante que hubiera de tomarse en cuenta.

A fin de destacar claramente esta situación, considérese el caso en que PEMEX eleva sus costos de operación mas allá de los propiamente requeridos en los procesos de extracción. En este caso, es claro que el ahorro corriente de PEMEX como contablemente medido, subestima el verdadero excedente generado.

La medición de "ahorro corriente" ha de ser una medición económica y no una medición contable; debiéndose evaluar el producto generado y los servicios de factores requeridos para su 
generación, en costo de oportunidad. De otra forma, el problema fundamental de medición se estará eludiendo, recurriéndose a la simplificación del "adecuado concepto contable".

El costo de oportunidad de las ventas domésticas está constituido por el valor del consumo doméstico calculado a precios internacionales.

Al proceder de esta forma, estamos reconociendo el costo o sacrificio que para PEMEX representa dejar de destinar parte de su producción al mercado externo para destinarlo al mercado doméstico. La diferencia entre las ventas de PEMEX así valuadas y lo que perciba de ingresos, nos mide la parte del producto generado por PEMEX que es transferido, vía subsidio, a los consumidores domésticos.

Los ingresos por exportaciones de PEMEX, se deben también ajustar por una estimación realista de los precios internacionales que se esperan en el futuro y por un precio sombra para las divisas.

Esto es así porque el valor para la economía, de las divisas que PEMEX genera, es implícitamente el valor que se le asigne a la disposición de un mayor flujo de bienes y servicios importados.

De igual forma, los recursos que utiliza PEMEX, y en particular, los servicios de mano de obra y de capital, deberían valorarse en términos de lo que la economía deja de producir al transferirlos a PEMEX.

El excedente económico calculado de esta manera no coincide necesariamente con el Excedente Financiero de PEMEX, pues parte del excedente económico se está destinado para subsidiar al consumo doméstico y a los sueldos arriba del costo social de la mano de obra.

Debemos, sin embargo, separar la generación del excedente de su destino, pues éste último, es uno de los principales instrumentos que deben manejarse dentro de la nueva estrategia de desarrollo. 
Excedente económico bruto y neto

El concepto bruto es igual al superávit de operación e incluye la aportación del capital en la generación del mismo.

La aportación neta de capital al excedente, la podemos medir en términos de lo que éste factor rendiría en su mejor uso alternativo, el cual estaría determinado por la eficiencia marginal de la inversión de la economía y tendría como límite inferior la tasa de interés de la deuda externa."

El costo de oportunidad de usar los activos que ya están en operación, es mucho menor que el costo de usar capital que provendrá de las inversiones programadas para el futuro.

Los activos que ya están en operación, tienen muy limitadas alternativas otras a su uso actual, por lo cual, le podemos asignar un costo de oportunidad relativamente menor y aún de cero; en cambio, las inversiones programadas y aún no realizadas, tienen plena flexibilidad para destinarse a otros usos, por lo cual, su costo de oportunidad es mayor.

El Excedente Económico Neto, nos indica la aportación de PEMEX al incremento de la riqueza nacional, pues ya se ha deducido del valor de la producción el valor social de los recursos que usó PEMEX para generar dichos excedentes.

\section{Generación y disposición de los excedentes.}

Si bien, el Excedente Económico Neto generado nos indica el incremento de extracción y realización de riqueza, la política económica nacional debe decidir sobra la distribución del Excedente Económico Bruto, ${ }^{* *}$ cuyas principales opciones serán:

a) Inversiones adicionales a PEMEX para reponer y/o ampliar su capacidad.

* Dentro del "costo de uso" de capital habrá que incluir, por supuesto, la depreciación del capital.

** Si el Gobierno Federal decidiera sólo sobre la distribución del excedente neto, estaría dejando a PEMEX la decisión sobre los fondos de depreciación y los rendimientos netos de capital 
b) Adiciones netas al consumo y/o inversión en el resto de la economía previa transferencia del excedente de Pemex al Gobierno Federal ${ }^{* * *}$

c) Subsidio al consumo nacional de energéticos

La distribución entre consumo o inversión en el resto de la economía depende de los objetivos del Plan de Desarrollo.

La decisión entre inversión petrolera y no petrolera dependen, obviamente, de la rentabilidad de nuevas inversiones de PEMEX en comparación con lo que se obtendría en el resto de la economía.

La política de subsidio al uso doméstico de energéticos debe tomar en cuenta, en contrapartida a los beneficios, los siguientes costos sociales:

a) Se favorece la concentración urbana, pues las grandes ciudades requieren de un alto consumo per cápita de energéticos para el transporte, debido a las grandes distancias que se tienen que recorrer. La eliminación de subsidio acercaría el costo privado al costo social.

b) Con energéticos más baratos se promueve la sustitución de energía petrolera por mano de obra menos calificada, cuyo principal recurso es la oferta de energía humana.

c) Se favorece el uso dispendioso de los energéticos, tanto en consumo como en proyectos de inversión. Se podrían obtener mayores rendimientos si se economizara el consumo doméstico para generar excedentes exportables adicionales.

La generación de excedentes y su patrón de extracción.

La generación de los excedentes depende de la eficiencia operativa de PEMEX, de la calidad y profundidad de los yacimientos petroleros y del valor que el mercado le asigne al producto.

\footnotetext{
*** Los impuestos federales constituyen solamente un mecanismo de transferencia que pueden destinarse a mayor consumo
} o inversión. 
La generación de excedentes es afectada por el patrón temporal de extracción de la riqueza petrolera, como enseguida explicamos.

Si la extracción se adelanta demasiado, los costos sociales se incrementarán al presionarse sobre la demanda de los recursos domésticos con oferta relativamente inelústica, tales como: transporte, construcción, mano de obra calificada. Así mismo, al adelantar las ventas se corre el riesgo de desaprovechar la oportunidad de vender en el futuro a un precio más alto.

Si se defiere la extracción de petróleo, se pospone el uso de los excedentes con los que, de otra forma, se podría obtener un rendimiento cuando menos igual a la tasa de interés que nos ahorraríamos sobre la deuda externa; pero, en contrapartida a esos costos, se obtendría una ganancia adicional, al aprovechar el incremento de precios.

En los cálculos realizados se hace el supuesto simplificatorio de que el patrón de inversiones y extracción para 1979-1982 es el adecuado. En un estudio más profundo debería hacerse un ejercicio simultáneo de generación y patrón de extracciones, que nos dé el máximo de excedente.

\section{El excedente financiero}

Este concepto es de mucha utilidad para analizar el impacto del sector petrolero sobre las fluctuaciones del mercado de divisas y sobre el crecimiento de la oferta monetaria.

El impacto sobre el mercado de divisas depende también del comportamiento de la balanza de pagos del sector no petrolero, pero se espera que sus entradas y salidas de divisas a lo largo del año, tengan una distribución normal, de tal manera que las fluctuaciones bruscas de una determinada unidad de dicho sector, no afectarán significativamente el comportamiento total.

Sin embargo, el comportamiento financiero de PEMEX sí puede afectar significativamente el comportamiento total; por ejemplo, si las importaciones de PEMEX se retrasan, se incrementarán las reservas internacionales y el medio circulante, poniendo transitoriamente en peligro la estabilidad de precios y de la tasa de cambio.

\footnotetext{
${ }^{*}$ Habrá que hacer un ajuste si se esperan incrementos en los costos de extracción.
} 
Se debe adecuar la política monetaria de flujo de caja de PEMEX para esterilizar oportunamente cualquier impacto desestabilizador. 


\section{APÉNDICE 7}

\section{$\underline{\text { Los Coeficientes Medio y Marginal Capital/Producto }}$}

El coeficiente capital-producto $(k)$ de 1950 a 1975 se mantuvo con un valor alrededor de 2.83, con una ligera tendencia a decrecer de 1950 a 1970 y a aumentar desde 1971. El coeficiente incremental capital-producto $(w=\Delta \mathrm{K} / \Delta \mathrm{Q})$, no muestra ninguna tendencia pero naturalmente registra mayores variaciones que el promedio $(K / Q)$, y tuvo una media de 2.85 durante 1950-1975. Enseguida presentamos los valores de $\mathrm{k}$ y de $w$.

\section{Coeficiente Medio e Incremental Capital-Producto}

$$
(" k ", \text { "w") }
$$

\begin{tabular}{|c|c|c|c|c|c|c|c|c|c|}
\hline Concepto & $51-55$ & $56-60$ & $61-65$ & $66-70$ & $71-75$ & 1976 & 1977 & $51-70$ & $51-75$ \\
\hline$k=(\mathrm{K} / \mathrm{\Omega})$ & 2.96 & 2.88 & 2.96 & 2.64 & 2.75 & 3.030 & 3.15 & 2.80 & 2.81 \\
\hline$w=(\Delta \mathrm{K} / \Delta \mathrm{Q})$ & 2.62 & 2.76 & 2.38 & 2.54 & 3.98 & 10.0 & 7.0 & 2.60 & 2.86 \\
\hline$g=$ Crecimiento medio anual del & 5.58 & 5.71 & 7.10 & 6.90 & 5.70 & 2.1 & 2.8 & 6.32 & 6.19 \\
\hline $\begin{aligned} b= & \text { Coeficiente de inversión entre } \\
& \mathrm{PIB}=(\mathrm{g})(\mathrm{w})\end{aligned}$ & 14.62 & 15.76 & 16.90 & 17.53 & 22.69 & 21.00 & 19.6 & 16.43 & 17.73 \\
\hline
\end{tabular}

Como se puede observar en el cuadro anterior, no existe diferencia significativa entre los promedios anuales de 1951 a 1975 de "k" y los de "w", w es menor que k para el promedio anual de 1951-1970, lo cual es congruente con la ligera declinación que se observa en k durante dicho período."

\footnotetext{
${ }^{*}$ El diferencial total de $\mathrm{k}$, $\mathrm{dk}$, es igual:

$d k=\frac{\mathrm{Qdk}}{\mathrm{QQ}}-\frac{\mathrm{KdQ}}{\mathrm{QQ}}=\frac{\mathrm{dQ} \mathrm{dK}}{\mathrm{Q} d \mathrm{Q}}-\frac{\mathrm{KdQ}}{\mathrm{Q} \mathrm{Q}}$

$d k=\mathrm{g}(\mathrm{w}-\mathrm{k}) ;$ en donde $\mathrm{g}=\mathrm{dQ} / \mathrm{Q}$ y $\mathrm{Q}=\mathrm{PIB}$ real

Por lo tanto si $\mathrm{w} \angle \mathrm{k} \mathrm{dk} \angle 0$, es decir, $\mathrm{k}$ es decreciente.
} 
Durante los últimos 6 ó 7 años se ha revertido la tendencia ligeramente decreciente de k, y gran parte se explica por el incremento en la participación de las inversiones pública intensivas de capital.

Por otro lado, el comportamiento de "w" de 1950 a 1970 no muestra ninguna tendencia significativa y fluctúa alrededor de una media de 2.6. Si agregamos la información de la primera mitad de los setentas, el promedio de "w" sube a 2.8 debido al incremento que registró en los años de recesión de 1971 y 1975 cuando la "w" sube a más de 5.0.

Durante los años de declinación de la tasa de crecimiento del PIB (" $g$ "), se observa un drástico incremento en la "w", debido a que la disminución de "g" es mucho mayor que la del coeficiente de inversión como porcentaje del PIB (" $b ")$. En forma simétrica, el "w" baja cuando se recupera la tasa de crecimiento."

El coeficiente incremental promedio "w", se puede usar para proyectar las necesidades de inversión si las tasas de crecimiento del PIB ("g") no varían mucho y la economía se ha estabilizado, como será el caso de las "g" proyectadas para 1980, 1981 y 1982. En estas condiciones es confiable usar el "w" promedio; por ejemplo durante el período 1965 a 1970 el "w" casi no registró variaciones como se puede observar en la gráfica adjunta. Durante 1978 y 1979 esperaríamos que el "w" continuara cayendo pero conservando niveles mayores que los históricos, ya que en 1978 y 1979 esperaríamos que el "w" continuara cayendo pero conservando niveles mayores que los históricos, ya que en 1978 no habrá un cambio tan radical en "g" como para que "w" bajara a niveles menores de la media, como sucedió de 1962 a 1964, al pasar "g" de 4.7\% en 1962 a "g" de 11.2\% en 1964 y la "w" pasó de 3.62 a 1.74 (véase el gráfico de la siguiente página).

Otra razón para esperar una "w" alta en 1978 y 1979 es porque en dichos años se recuperarán las inversiones públicas y privadas y el impacto de dichas inversiones sobre el producto se pondrá cuando menos un año. Este rezago ayuda a explicar también el decrecimiento posterior de "w".

Como puede verse en la gráfica, los años 1952-53, 1959, 1971 y 1975-76-77 son períodos en los que hay una drástica declinación de "g" cuya media anual es de $2.8 \%$, mientras que en los dos años

** Recuerde que $w=(\mathrm{b} / \mathrm{g})$, y por lo tanto $\mathrm{w}=\frac{\mathrm{b}-\mathrm{g}}{(1+\mathrm{g})}$ donde es el operador del incremento porcentual. 
anteriores a esos períodos, la "g" alcanzó un promedio de 7.2\%. El "w" promedio anual de los años de “auge" fue de 2.7 y el "w" promedio es de 2.86 para todo el período.

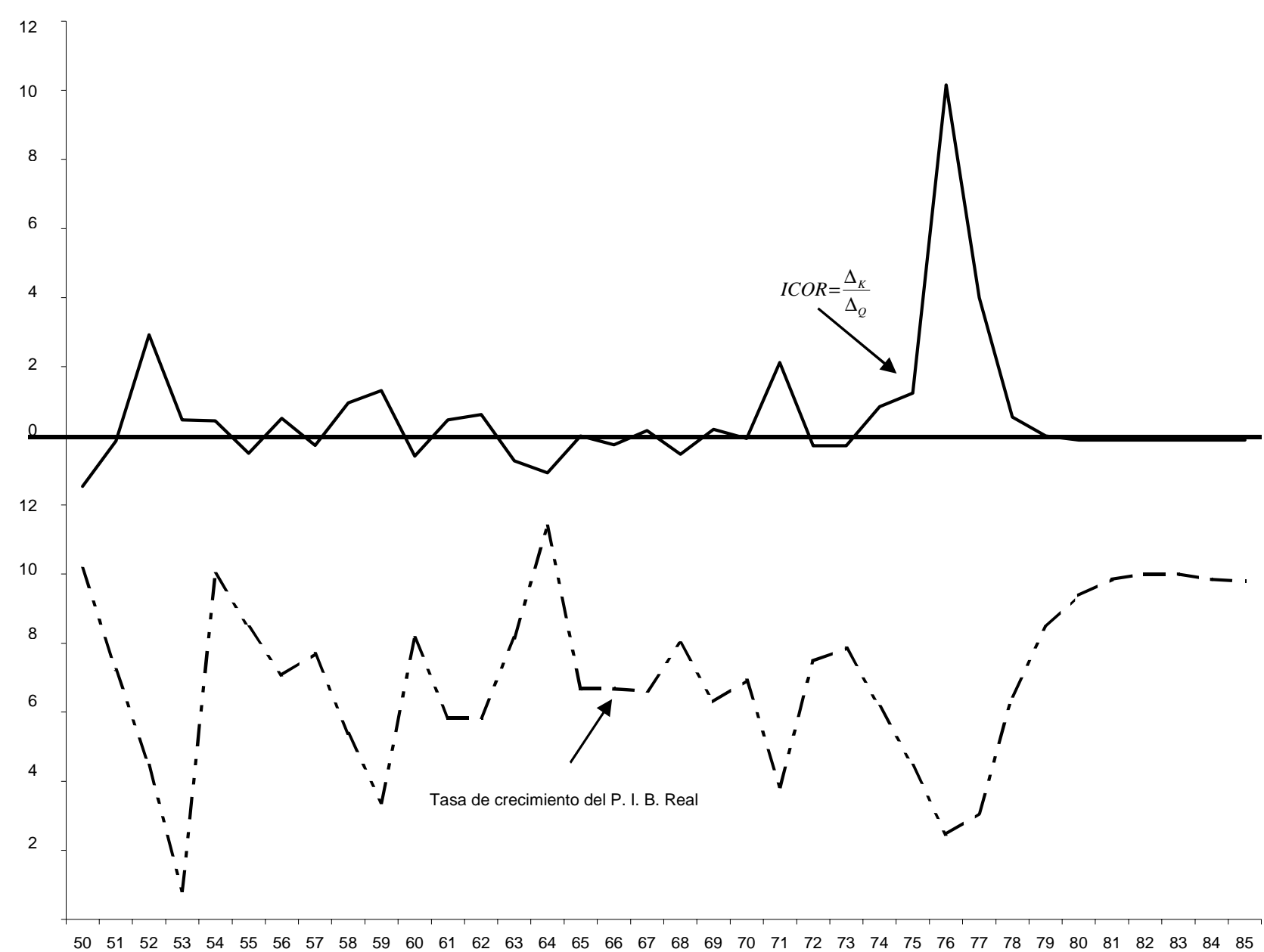

La relación capital sobre producto que tendremos durante el próximo quinquenio será mayor que la media histórica pero registrará una tendencia decreciente. En promedio será de 3.1 y pasará de 3.18 en 1978 a 3.08 en 1982 . Esta tendencia decreciente es congruente con el hecho de que w sea menor que $k$.

La tasa de crecimiento del producto está determinada no sólo por el crecimiento del capital sino también por el trabajo. La relación $1 / \mathrm{w}$ nos da una productividad "marginal" del capital: $(Q / K)$, pero que es "marginal" entre comillas porque incorpora también la contribución del resto de los 
factores, entre otros, la del trabajo." Por lo tanto, el uso de "w" para obtener los requerimientos de inversión es válido en la medida en que no haya cambios significativos en las contribuciones relativas de los diferentes factores, lo cual podemos suponer razonablemente para los próximos 5 años.

De 1978 a 1982 el capital crecerá a una tasa media anual del 7.8\% y el empleo lo hará a una tasa del 4.0\%; si sustituimos estos valores en la función de producción que hemos estimado: $Q=(1 / 47) \mathrm{K}^{.97} \mathrm{~L}^{.31}$, obtendremos una tasa de crecimiento del PIB real igual a $8.8 \%$, que es cercana al $8.1 \%$ que obtenemos para el quinquenio en nuestro ejercicio macroeconómico.

Esta discrepancia se debe a que la función de producción es aplicable para condiciones de largo plazo cuando la capacidad del capital y de la mano de obra se utiliza "normalmente", por ejemplo en los últimos tres años del quinquenio: 1980, 1981 y 1982.

\footnotetext{
Habrá que considerar también la contribución de capital humano, las economías a la escala, el aumento de la eficiencia
} en la asignación de recursos, el cambio tecnológico, etc. 
Producto Interno Bruto, Coeficiente de Inversión

y Relación Incremental Capital - Producto

\begin{tabular}{cccc}
\hline & $\begin{array}{c}\text { PIB } \\
\text { A N O S }\end{array}$ & $\begin{array}{c}\text { IFBT } \\
\text { Tasa de Crecimiento }\end{array}$ & I C O R \\
& $(1)$ & $(2)$ & $\begin{array}{c}\text { I C } \\
(3)=(2) /(1)\end{array}$ \\
\hline 1961 & 4.9 & 17.1 & 3.5 \\
1962 & 4.7 & 17.2 & 3.7 \\
1963 & 8.0 & 18.3 & 2.3 \\
1964 & 11.7 & 20.4 & 1.7 \\
1965 & 6.5 & 19.6 & 3.0 \\
1966 & 6.9 & 20.0 & 2.9 \\
1967 & 6.3 & 21.3 & 3.4 \\
1968 & 8.1 & 22.0 & 2.7 \\
1969 & 6.3 & 21.8 & 3.5 \\
1970 & 6.9 & 22.2 & 3.2 \\
1971 & 3.4 & 20.0 & 5.9 \\
1972 & 7.3 & 21.9 & 3.0 \\
1973 & 7.6 & 23.7 & 3.1 \\
1974 & 5.9 & 23.9 & 4.1 \\
1975 & 4.1 & 24.2 & 5.9 \\
1976 & 1.7 & 21.9 & 12.9 \\
1977 & 3.2 & 19.9 & 6.2 \\
\hline
\end{tabular}

Tasa de crecimiento real

Fuente: Banco de México. Serie Información Económica, Producto Interno Bruto y Gasto 1960 - 1977. México, agosto de 1978.

ICOR $1961-1970=\frac{29.9}{10}=3.0$

ICOR $1961-1975=\frac{51.9}{15}=3.5$

ICOR $1971-19705=\frac{22}{5}=4.4$

ICOR $1961-1977=\frac{71}{17}=4.2$

ICOR $1971-1975=\frac{41.1}{7}=5.9$ 


\section{APÉNDICE 8}

\section{$\underline{\text { La Elasticidad Producto del Empleo }}$}

De 1960 a 1970, el empleo creció a una tasa media anual del 2.9\% y el producto real a un 7\%, es decir, por cada 1\% de incremento en el PIB el empleo ( $\%$ en el empleo / \% en el PIB real) de 0.41. Durante la primera mitad de los 70's se registró un incremento substancial en la elasticidad como resultado de la recesión de los últimos tres años, como enseguida explicaremos.

De 1970 a 1975 el empleo creció a una tasa media anual de 3.4 y el producto a 5.6\%, es decir, la elasticidad del empleo ascendió a 0.60. Este incremento en el coeficiente de elasticidad se presentó sobre todo en los últimos años: de 1973 a 1975 la elasticidad fue de 0.69.

Los mayores valores de la elasticidad de los últimos años se explican porque durante el período de desaceleración del crecimiento del PIB la tasa de crecimiento del PIB disminuyó más que la tasa de crecimiento del empleo, debido a que durante el período de recesión los empresarios esperan que la caída de la demanda (o del crecimiento de demanda) sea transitorio y por lo tanto no desemplean tanto personal como en el caso de que las expectativas fueran de una caída permanente; es el resultado de optimización de la inversión en costos de transacción asociados al desempleo, recontratación y adiestramiento de personal. Durante el período de recesión se presenta entonces no sólo un aumento en la capacidad de capital no usado sino también en la mano de obra ("labor hoarding").

Sin embargo, la acumulación de mano de obra en exceso cesó en 1976-1977. Durante 1976 y a principios de 1977 se agudizó el grado de incertidumbre sobre el futuro económico de México y disminuyó la confianza en una rápida recuperación, además, hubo una drástica declinación en la producción de industrias muy intensivas en mano de obra no calificada, como es el caso de la construcción.

Debido a estas circunstancias, el despido de personal se agudizó durante el año de 1977. En este año, la elasticidad bajó bruscamente por la disminución absoluta en el empleo y porque el crecimiento del producto fue positivo. Por ejemplo, en la industria de transformación el valor agregado aumentó en 1977 en 3\%, mientras que el empleo disminuyó en 1.6; en 1976 se registró un incremento 
de $2.8 \%$ en el producto y $1.8 \%$ en el empleo (elasticidad igual a 0.64 ) y en 1975 el producto aumentó en $4.2 \%$ y el empleo en $2.6 \%$ (elasticidad igual a 0.61 ).

Durante 1978 estimamos que la elasticidad del empleo fue mayor que la normal por las siguientes razones:

a) 1978 fue todavía un año de transición y de reafirmación de la confianza y prevaleció aún la incertidumbre respecto a una recuperación definitiva. Ante estas expectativas, es de esperarse una mayor contratación de factores "variables" (trabajo) que de factores "fijos" (capital).

b) En 1977 se intensificó, más allá de lo normal, el desempleo de personal en exceso como respuesta a la sobreestimación de la crisis; será necesario entonces aumentar el empleo en 1978 en un porcentaje mayor que lo que haría en el largo plazo para así recuperar los niveles normales.

Por todas las razones arriba aducidas, estimamos que en 1978 habrá una elasticidad de 0.60 y que en 1980 alcanzará los valores normales de 0.45 , pasando por un valor intermedio de 0.50 en 1979 .

La elasticidad de largo plazo de 0.45 , es consistente con lo que se obtiene de una función de producción que estimamos para el período "normal" 1950-1970 y cuya ecuación es la siguiente:

$$
\begin{aligned}
& Q=(1 / 47) \mathrm{K}^{.97} \mathrm{~L}^{.31} \text { en donde } \\
& Q:=\text { es PIB real } \\
& K .=\text { es el acervo de capital físico } \\
& L .=\text { es la mano de obra empleada }
\end{aligned}
$$

$\hat{Q}=.97 \hat{\mathrm{K}}+.31 \hat{\mathrm{L}}$, donde $\wedge$ es el operador de cambios porcentuales. 
De acuerdo al presente ejercicio, durante los próximos cinco años, el capital aumentará en una tasa promedio del 7.8\% y la mano de obra empleada en 4\%, si estas cifras las introducimos a la función de producción nos da un $\hat{Q}=8.8 \%$ y una elasticidad total de empleo igual a 0.455 , que está muy cercana a nuestro supuesto de 0.45 . Esta elasticidad es válida para una situación de largo plazo como ya lo hemos explicado. 